\title{
0 momento, os desafios e as possibilidades da análise econômica territorial para o planejamento do desenvolvimento nacional
}

\author{
Francisco de Assis Costa*
}

\begin{abstract}
Palavras-chave
desenvolvimento endógeno, planejamento do desenvolvimento, desenvolvimento local

Classificação JEL

O20

\section{Keywords}

endogenous and sustainable development theories, development planning, local development, local and regional innovation system

\section{JEL Classification}

\section{Resumo}

$\mathrm{O}$ artigo pretende contribuir para a superação dos desafios relativos à capacidade de análise e de atuação para o desenvolvimento regional e territorial. Para tanto, discute a relação entre conhecimento e planejamento - entre ciência e ação baseada em ciência. Após uma análise dessa relação, no período anterior à prevalência da tese da New Public Management, na qual deverão ser investigadas as condições que levaram ao fracasso das estratégias do planejamento do desenvolvimento no pós-guerra, pergunta-se se se observa, desde então, evolução nas ciências da sociedade que possa oferecer base ao planejamento de um desenvolvimento fundamentado em crescimento, equidade e sustentabilidade. A partir daí, explora-se a possibilidade de as teorias do desenvolvimento endógeno e sustentável (TDES) subsidiarem novos processos de planejamento. Nessa tarefa, o foco principal é posto nas noções de clustering, de trajetórias tecnológicas, de cadeias de valor, de economias locais e regional.
\end{abstract}

\section{Abstract}

The article aims to contribute to overcoming the challenges regarding the capacity of analysis and action for regional and territorial development. In order to do so, it discusses the relationship between knowledge and planning - between science and sciencebased action. Following an analysis of this relationship, during the period prior to the prevalence of the New Public Management theories in which the conditions leading to the failure of the postwar development planning strategies are investigated, we ask ourselves if any developments in the sciences of society that may offer grounds for planning a development based on growth, equity and sustainability have been seen. From there, this article explores the possibility that theories of endogenous and sustainable development (TESD) can support new planning processes. The main focus, in this task, is placed on the concepts of clustering, technological trajectories, value chains, and local and regional economies. 


\section{1_Introdução}

Os anos oitentas assistiram a um amplo movimento de reformas do Estado em todo o mundo capitalista com o proclamado intuito de corrigir as distorções produzidas pelo consenso keynesiano prevalecente desde o pós-guerra. A visão que se fez dominante era de que os problemas do capitalismo se assentavam num excesso de intervenção e presença dos Estados nacionais resultante da ênfase na gestão da demanda efetiva, seja quando garantem estruturas de bem-estar social nos países industrializados, seja quando, munidos de estruturas de planejamento, sustentam, por toda parte, em particular nos países do Terceiro Mundo, investimentos em infraestrutura e capacidade produtiva de bens e serviços necessários ao crescimento.

Em qualquer dos casos, põe-se em movimento de contra-arrestação um liberalismo renovado amparado em mobilizações acadêmicas e políticas. No plano intelectual, ampara-se na public choice theory (PCT), perspectiva teórica que aplica os pressupostos analíticos da economia neoclássica à política, defendendo que as pessoas que trabalham nas organizações do Estado, em última instância, maximizam o interesse próprio, tendência que, nas orientações do Estado do bem-estar e nos programas de desenvolvimento baseados no investimento estatal, encontra expressão na expansão do orçamento, criando o excesso de oferta de produtos e serviços que tornaria o governo demasiadamente grande e ineficiente.

Nesse quadro, a relação do burocrata com o político assumiria a configuração de um monopólio bilateral, no qual, uma vez indicado pelo último o que produzir, o primeiro entra com o poder de informação e a capacidade de discriminar, no processo de planejamento, a quantidade produzida e o custo de produção (Moe, 2007). No plano político, o movimento de reação se sustenta na crítica da nova direita, que associa à hipertrofia do Estado a capacidade de extração de recursos da sociedade por esses segmentos em posição de influenciar as decisões de governo e de conduzir a implementação dessas decisões a partir de interesses internos ao próprio aparato estatal (Hood, 1995).

A grande reforma orientada pela new public management $(\mathrm{NPM})^{1}$ prometia um desenvolvimento como processo genuíno do crescimento econômico resultante da otimização pelos critérios dos mercados, tanto mais eficientes quanto mais desregulamentados, da alocação dos fluxos de recursos mediados pelo Estado, agora minimizados pela redução do papel da burocracia às funções de regulamentação e facilitação das atividades econômicas e de gerenciamento da qualidade dos serviços públicos residuais produzidos por parcerias público-privadas.

Depois de duas décadas de hegemonia, a NPM vem sendo criticada em seus fundamentos e resultados. Carneiro e Menicucci (2011,p. 33-37) identificam na literatura três fases da NPM. A primeira, que prevalece do início dos anos oitentas ao início dos noventas, constitui-se de mera sistematização das práticas orientadas pela agenda da nova direita em operação nos governos de Ronald Reagan, nos Estados Unidos, e Margareth Tatcher, na Inglaterra, e àquela altura dominante nos organismos internacionais de cooperação e desenvolvimento, em particular nos programas de ajuste estrutural propugnados pelo Banco Mundial e pelo Fundo Monetário Internacional. Em uma segunda fase, que ocupa a primeira metade dos anos noventas, encontram-se descrições sobre os diferentes estágios em que se situavam as reformas. Apenas na terceira fase, iniciada em fins dos noventas, estudos comparativos em diferentes países permitem os esforços analíticos que revelam surpresas e efeitos paradoxais nas reformas, cujo balanço se mostrou frustrante na maioria dos seus itens, seja porque se partiu de pressupostos equivocados e informações limitadas, seja porque, operando em contextos culturais diversos, se defrontou com impossibilidades de consenso 
que levaram a paradoxos institucionais, seja ainda porque, operando em sistemas complexos, os esforços levaram à descontinuidade e à não linearidade na aplicação da NPM.

Em resumo, as reformas do Estado e as reformas administrativas das duas últimas décadas do século passado não produziram os efeitos apregoados, gerando, antes, como observa Peters, já em 1996, um pernicioso esvaziamento do Estado, no que se refere à sua legitimidade na relação com a sociedade e seu poder de intervenção na economia e na sociedade; na sua capacidade de provisão direta de serviços e na desqualificação dos servidores públicos. Ademais, como salienta Chang (2004, p. 230), as políticas e as instituições recomendadas não levaram ao prometido dinamismo do crescimento, e, o que é pior, em muitos dos países em desenvolvimento o crescimento simplesmente cessou.

Nos anos 2000, o debate internacional abandonou a uniformidade em torno das reformas orientadas para o mercado, passando a indicar a necessidade de escolhas específicas ancoradas na criatividade e nas especificidades de cada país. A mudança de curso na agenda atual põe em relevo os desafios de formulação de vias alternativas de desenvolvimento e a discussão do papel do Estado nesse processo, em período que pode ser considerado como o pós-Consenso de Washington (Diniz, 2007).

A discussão do papel do Estado nesse novo contexto requalifica as noções de desenvolvimento e planejamento. Quanto ao desenvolvimento, parece estabelecida a necessidade de combinar os atributos de crescimento e equidade, ao par de garantir a elevação da capacidade das pessoas de fazer escolhas e exercer a cidadania. Posto assim, esses fins do desenvolvimento pressupõem consistência intergeracional na utilização dos recursos da natureza, fundamentos de última instância da reprodução social. O desenvolvimento deverá, assim, ser qualificado também pela esperança de sustentabilidade que apresenta.
Um processo de evolução social com tais qualidades requer atuação estratégica do Estado, particularmente nos países mais atrasados. Na América Latina, na perspectiva do ILPES/CEPAL, é necessário construir um tipo de Estado que permita superar as brechas em relação a outros países e alcançar o objetivo de crescimento com igualdade, daí o pressuposto do planejamento como definição de um projeto de país e de instrumentos para conduzir o processo de modernização da gestão pública e da sociedade (ILPES/ CEPAL, 2011). Nessa visão, a planificação tem as dimensões técnica e política articuladas como chave para a eficácia do processo de definição de prioridades por mecanismos capazes de garantir uma administração pública transparente e interativa com a sociedade civil.

Pensando o Brasil por ângulo semelhante, Cardoso Júnior (2001) argumenta que ao Estado cabe a tarefa de induzir, fomentar ou mesmo produzir as condições para a transformação das estruturas econômicas e sociais do país. Assim que se torna imprescindível reequilibrar e ressignificar as dimensões do planejamento governamental e da gestão pública, tratando-as como unidade de análise e de reconstrução da capacidade do Estado para o desenvolvimento nacional.

O planejamento que se cogita em todos os casos implica o funcionamento de mecanismos de governança participativa ou democrática - enquanto redefinição e ampliação das formas de interação sociedade-Estado; enquanto participação da sociedade nos processos decisórios e na gestão pública, em que se privilegia a pluralidade em espectro de atores para além das elites e em pluralidade de escalas; enquanto correção de déficits democráticos e garantia de accountability.

Um sistema de planejamento, assim visto, é sistema dinâmico, aberto e interativo de governança, em que a autoridade e a capacidade do Estado são acionadas em diferentes formas e escalas, para alcançar distintos resultados públicos. 
Em escala local, como qualificador das demandas organizadas nos territórios, do Estado se espera nova capacidade de antecipação, descrição e prospecção das dinâmicas territoriais, discernindo a diversidade de sujeitos, razões e perspectivas observáveis nesse nível, para que sínteses consistentes sejam produzidas.

Em escala nacional, a participação dos agentes do Estado deverá qualificar demandas organizadas em nível nacional, o que requer (nova) capacidade de leitura sistemática, diagnóstica e prospectiva, do país como um sistema de regiões - eis que aí o papel do Estado é o de supridor de necessidades do desenvolvimento como estratégia nacional.

Há dois grandes desafios para isso: o primeiro diz respeito à capacidade de conhecer - dispor dos elementos teóricos, metodológicos e empíricos para decodificar, acompanhar e prospectar as interações entre as especificidades naturais, a diversidade estrutural e a diversidade territorial que distinguem as regiões do país; conhecendo o país como um "sistema de regiões" - uma estruturação territorializada -, o segundo desafio será o de desenhar políticas de desenvolvimento que considerem a diversidade e de estabelecer capacidade técnica para que se avalie sistematicamente a dinâmica do desenvolvimento em sua diversidade territorializada.

Este artigo pretende contribuir para a superação dos desafios relativos à capacidade de análise territorial em nível local, compreendendo aí suas interações com realidades supralocais. Faz parte da empreitada discernir sobre a relação que há entre conhecimento e planejamento - entre ciência e ação baseada em ciência -, de um lado, e entre conhecimento, planejamento e desenvolvimento, de outro. Após uma incursão sobre essas relações no período anterior à NPM, na seção 1, onde se indagará sobre as condições que levaram ao fracasso das estratégias de planejamento do desenvolvimento que vigoraram no pós-guerra, perguntaremos na seção 2 se se observa, desde então, evolução nas ciências da sociedade que possam oferecer base ao planejamento de um desenvolvimento esteado em crescimento, equidade e sustentabilidade. Na seção 3, exploraremos as perspectivas teóricas do desenvolvimento endógeno e sustentável (TDES), procurando dar consistência às noções de clustering, de trajetórias e de cadeias e estabelecer suas posições-chaves na compreensão do desenvolvimento por percursos de generalização e por integração das categorias em um corpo teórico único da TDES.

Com base nesse esforço, espera-se oferecer elementos para desenvolver metodologias capazes de operar os ganhos teóricos e, assim, de avaliar a dinâmica dos territórios com capacidade de apreender seu desenvolvimento integrado ao desenvolvimento do Brasil.

\section{2_A constituição da problemática do espaço na economia e a questão do desenvolvimento: a dupla condição de objeto de teorização e de ação no período imediatamente posterior à Segunda Guerra Mundial}

Nas ciências da sociedade, todo conhecimento tem dupla existência: é ciência, consciência da razão porque a coisa é o que é, da forma como é; é também consciência da possibilidade de que a coisa poderia ser diferente mediante vontade orientada pela ciência. Na primeira condição, o conhecimento é logo; na segunda, techné. Milton Santos tinha clareza sobre esse duplo papel do conhecimento e problematizou a tensão que aí reside em trabalhos "[...] voltados à problemática do espaço considerado como objeto de teorização ou de planejamento" (Santos, 2007, p. 10, grifos meus, FAC). Recentemente, Sergio Conti e Paollo Giaccaria se debruçam em torno da mesma questão em reflexões sobre o que chamam as duas dimensões das teorias, a analítica e a normativa (Conti; Giaccaria, 2001, p. 95, grifos no original). Eles focali- 
zaram a dramática tensão do duplo papel do conhecimento no contexto das três décadas pós-Segunda Guerra Mundial, momento particularmente dinâmico em relação ao objeto que aqui nos interessa de perto - economia e desenvolvimento social referido a território.

Uma compreensão destacada nesses autores sobre essa fase refere-se a que os grandes programas de pesquisa orientados à compreensão do desenvolvimento (conhecimento como logo), então em andamento, patrocinados pela economia (regional) e a geografia (econômica), terminaram por se subordinar ao planejamento, enquanto estrutura de conhecimento de intervenção (techné) que se esforçava por se estabelecer como ciência. Como consequência,

\section{[...] uma política econômica determinada é [...] imposta à economia política [que assim] perdeu seu status científico e se tornou simples ideologia, cujo fito é persuadir Estados e povos das vantagens daquilo que passou a ser chamado desenvolvimento: a venda da ideologia do crescimento aos Estados, a imposição de uma ideologia de sociedade de consumo às populações. (Santos, 2007, p. 15)}

\section{Para Conti e Giaccaria,}

This transformation of theoretical conceptions into an operational proposition found full expression in functionalism, a Style of thought whose theoretical and epistemological premises have had great success in scientific thought and intervention policies in economic an social systems in the course of the $20^{\text {th }}$ century. [With the result] Modernity is represented here by the structural model operating in advanced capitalist countries, which became the normative frame of reference. (Conti; Giaccaria, 2001, p. 96, 102)
Anote-se que as argumentações se referem ao vasto movimento de ideias que marcou a fase de prosperidade da economia mundial compreendida pelas três décadas que se seguem à Segunda Guerra Mundial. Trata-se, ademais, de um momento brilhante para as ciências econômicas regionais e para a geografia. Nesse fértil período, abundam demonstrações da descontinuidade espacial e descrições da hierarquia espacial prevalecente no mundo capitalista, num primeiro momento por modelos gravitacionais que atribuíam as configurações regionais e sua reprodução à determinação dos fluxos econômicos entre os lugares, diretamente, pelo tamanho das populações, inversamente, pelas distâncias respectivas; num segundo momento, substituindo, na mesma construção as populações, pelo poder de compra (Stewart, 1948; Isard, 1956).

Tais metáforas, não obstante a capacidade descritiva,é dizer, o poder de "fotografar" os objetos em sua disposição, contribuíram pouco para o esclarecimento do processo de constituição e destino das configurações em questão. A noção de polo de crescimento, introduzida por Perroux (1965), associada às contribuições de Hirschman (1958), expunha os fundamentos da polarização empiricamente verificável na dinâmica dos efeitos concatenados para a frente e para trás (linkages), de cada impacto produzido por uma capacidade produtiva nova - uma unidade motriz ou um conjunto de unidades motrizes capazes de exercerem efeitos geradores sobre outro conjunto econômico territorialmente definido (Perroux, 1961, p. 115). As teses de Myrdal, por seu turno, ao estabelecerem a recorrência dos eventos que produzem tais efeitos, indicam que processos de "causação cumulativa" explicam tanto "círculos virtuosos" de riqueza em ponto privilegiado quanto "círculos viciosos" de agravamento da pobreza no restante do país (Myrdal, 1957, 1972).

Inicialmente, duas posições simétricas se formaram em torno dessas construções seminais. A que defende a ideia de 
que desigualdade, tratada como descontinuidade espacial, é condição reversível espontaneamente e a que advoga que se trata de situação irreversível. Hirschman (1958, p. 213) indica a possibilidade de reversibilidade espontânea das diferenças - a ocorrência de convergência por processos que sintetiza na sua categoria de "contágio": a noção de que, ao efeito de "polarização", devida a economias de escala complementadas por externalidades, a que Krugman chama de complementaridade estratégica (Krugman, 1995), segue um efeito de "contágio", de modo que se o crescimento se faz duradouro, a descentralização ocorre. As pesquisas de Williamson (1965, 1968), que corroboram essa hipótese para os países desenvolvidos, têm seus resultados e conclusões estendidas por Pederson e Stohr (1969) para todo o mundo.

Na vertente oposta, Norro (1972) e Friedman (1963) seguem Merhav (1969, p. 48-49) no enunciado de que, nos países subdesenvolvidos, o “[...] fenômeno não é transitório, mas constante e estrutural, sendo primordialmente resultante das restrições técnicas que marcam seus processos de desenvolvimento".

Santos reconhece essas posições, em relação às quais apresenta uma terceira e, para seus argumentos, decisiva posição:

\section{A posição de B. Berry (1971, p. 139), para quem 'o crescimento não pode descentralizar-se espontaneamente', não é apenas uma posição intermediaria ou simbiótica entre a daqueles que vêem a macrocefalia como uma tendência irreversivel e a daqueles que a consideram como uma fase dos processos de crescimento. Para Berry, a reversão da tendência deve ser desejada e planejada. (Santos, 2007, p. 80 grifos meus, FAC)}

A "Posição de Berry" não é, indica o autor na citação acima, mera solução teórica de enunciados opostos sobre um mesmo objeto - uma síntese construída na antítese das posições. Trata-se, na verdade, de um desfecho, em dois atos, da tensão entre as condições logo e techné do conhecimento acumulado pelas ciências regionais - economia e geografia - sobre o desenvolvimento.

O primeiro ato implica o reconhecimento de que, não obstante com limites, a reversão das desigualdades no quadro institucional do capitalismo pode ser produto do desejo, da decisão e da ação política - do planejamento, da disposição planejada, pois; o segundo ato, por seu turno, pressupõe o entendimento de que, na materialização dessa disposição, se recorrerá a todo conhecimento, tanto o que disseca os mecanismos de irreversibilidade quanto o que esmiúça causas de situações revertidas.

Vista por outro prisma, a "Posição de Berry", com o discernimento, exige práxis - isto é, ação social orientada pela ciência; como tal, é postura que comanda uma releitura do conhecimento acumulado como "ciência regional" $(\log o)$ numa perspectiva de ação própria a uma "ciência do planejamento" (techné). O movimento resultará num quadro em que o conhecimento se legitima quando apropriado como protocolo da práxis. Nesse ponto, poder-se-á cogitar que a dimensão logo foi subordinada à dimensão téchne de um programa de conhecimento.

Para Conti e Giaccaria, esse processo estabelece uma "razão funcionalista", para a qual:

The assumption of an adequate social order cannot be separated from the inspiring principles of strategies and policies aimed at correcting the mode of functioning of modern society, which finds cohesion in the efficiency of the state, in the Fordist corporation and in appropriate economic planning activities.

(Conti; Giaccaria, 2001, p. 97) 
Nessa perspectiva, o desenvolvimento é expansão do sistema pensado como "capitalismo organizado" (Lash; Urry, 1987) a demandar uma ordem na qual papéis e funções podem ser claramente identificados e planejados - ao passo que fatores de perturbação, por engenharia social adequada, são passíveis de eliminação (Conti; Giaccaria, 2001, p. 97).

O planejamento, como (toda) práxis, envolve sujeito, objeto e processo: ação e retroação coordenadas e controladas por conhecimento e experiência, orientadas a fins compatíveis com devir alternativo ao destino. A vasta crítica de Santos sobre o planejamento no Terceiro Mundo dos anos setentas abarca todos esses elementos. Por inferência, poderíamos formular assim suas questões de fundo: Se o conhecimento científico resulta legitimado pela práxis, o quelegitima esta última? Se a resposta é a política, a questão é como compatibilizar os objetivos (conhecimento como logo) e regras de campo (Bourdieu, 1994) daquela (crítica, autonomia, isenção), com os desta última (conhecimento como techné: protocolo de ação forjado sobre compromisso para controlar danos de dissenso)?

Sobre o sujeito do planejamento no Terceiro Mundo, Santos indaga sobre a efetiva condição do Estado em contrariar as forças de expansão do grande capital internacional, de quem é tributário (Santos, 2007, p. 32), para contra-arrestar tendências iníquas, tanto espacial quanto socialmente; sobre o objeto questiona se, nas sociedades cindidas do Terceiro Mundo, é possível ao planejamento do desenvolvimento ter como objeto o conjunto do corpo social (Santos, 2007, p. 34).

Por fim, sobre o processo, indaga se é possível que a prática da intervenção planejada produza desenvolvimento efetivo, se baseada em uma ciência que, por ter-se subordinado à pragmática, se torna incapaz de cumprir seu dever de bússola na busca de um futuro sem pobreza, livre e harmônico - desenvolvido (Santos, 2007).
Não obstante a importância dos demais, este último é um ponto central na reflexão. A opinião de Santos é de que as ciências sociais regionais falharam em seu papel de desvendamento $(\log o)$ quando, objetivamente, se tornaram incapazes de incorporar a segmentação estrutural que marca a espacialidade dos países do Terceiro Mundo:

\section{Nenhuma das teorias espaciais leva em conta a existência de um outro subsistema econômico, coexistente com a economia moderna [...]. Os economistas ortodoxos só se interessam pelos mecanismos da economia moderna. Ora, isto impede a compreensão da economia global e de sua projeção no espaço. (Santos, 2007, p. 81)}

Nos espaços diferenciados, segue o autor, “[...] dois subsistemas, o 'circuito superior ou moderno' e o 'circuito inferior', podem ser isolados e identificados” (Santos, 2007, p. 126). O circuito superior seria resultado direto da modernização tecnológica incorporada a sua referência estrutural fundamental, os monopólios, cujas relações são supralocais, referidas a planos nacionais e internacionais. $\mathrm{O}$ circuito inferior far-se-ia enraizado nos fundamentos locais, voltado especialmente para a população pobre e baseado em atividades de pequena escala (p. 126).

A menção às pequenas empresas como fundamento estrutural, entendendo-as como realidade compatível com o desenvolvimento capitalista e o processo de acumulação, supera a visão marxista tradicional, para a qual o processo de concentração e centralização é linear e irrecorrível. E, nisso, converge com Edith Penrose, cuja teoria da convivência duradoura das pequenas e das grandes empresas, apresentada já em 1959 (Penrose, 2006, p. 319-337), constitui importante avanço às visões dualistas tradicionais baseadas em indivi- 
dualismo metodológico, as quais, não obstante, reconhecendo a permanência de segmentos de grandes e pequenas empresas, atribuíam a estas últimas existência necessariamente passageira, acidente histórico de rápida superação. De modo que, transpondo os limites do estruturalismo marxista e do atomismo, uma e outra perspectiva, a de Santos e a de Penrose, veem segmentações ou dualidades como imanentes à natureza das economias reais, os diferentes setores e atores que disso emergiriam desempenhando papéis essenciais para o funcionamento do sistema como um todo.

Sem a consideração desses aspectos, insistia Santo, e as formas específicas que assumem em cada situação - mais dramáticas no Terceiro Mundo, embora importantes, também, em muitos países industrializados - a "ciência do planejamento", ou aquilo em que se tornou a "ciência regional" dos modelos funcionalistas e a práxis que orientou teriam se tornado temeridades, em razão de persistência e aprofundamento da iniquidade, revés de sua eliminação.

Em relação aos países pobres, a conclusão de Santos é pungente:

\section{[...] a lista das causas do subdesenvolvimento e da pobreza no Terceiro Mundo não pode estar completa antes que se dê a devida ênfase à importância do papel desempenhado pelo planejamento [...que...] tem sido um instrumento indispensável à manutenção e ao agravamento do atraso dos países pobres, assim como ao agravamento ou à exacerbação de disparidades sociais. (Santos, 2007, p. 13)}

No que se refere aos países industriais, a crise iniciada nos anos setentas alongou-se na década seguinte, revelando de diferentes modos a falência da teoria funcionalista do planejamento. Para Conti e Giaccaria,
[...] it was specially the 'weakest' regions which were affected by the general recession that hit the Western economies [in the seventies]. The outcome of thirty years of regional policies was clear to the eyes of all: an uninterrupted chain of geographical and cultural 'ruptures' and - from economic point of view - the substantial under use of the (economic, historical and ecological) potential of the regions involved in the development programs. (Conti; Giaccaria, 2001, p. 103)

\section{3_A problemática espacial do desenvolvimento em contexto sem teoria e sem planejamento}

Até meados do século passado, modelos neoclássicos, denominemos tradicionais, que relacionavam uma dimensão macro da economia, em equilíbrio geral produzido por ação dos mecanismos de mercado submetidos à força da lei dos rendimentos decrescentes de todos os seus componentes, com uma micro dimensão constituída de empresas, no dizer de Penrose (2006, p. 11), "[...] sem qualquer conteúdo interior", e consumidores, ambos agentes dominadas por racionalidade maximizadora padrão, dominavam a perspectiva regional da economia. A abordagem considerava irrelevantes as condições objetivas que medeiam tais relações, pois entendia que eventuais diferenças ou desequilíbrios seriam inevitavelmente eliminados. Como corolário, a noção de que o desenvolvimento, no que importa, equivale a esse processo de convergência que, ao fim e ao cabo, instituiria a modernidade do capitalismo.

Nas três décadas que se seguem à Segunda Guerra Mundial, constituiu-se um campo de estudos do desenvolvimento, com destacados papéis de economistas e geógrafos, cujos resultados indicavam que as descontinuidades espaciais expressas em polaridades representavam mais que diferenças 
de grau em processo histórico linear e teleológico. Considerando o todo do debate, em que se inclui a crítica que aponta constituições diversas dos polos por dualismos e segmentações produzidas pela história nos territórios, indicavam-se estruturações diferenciadas e únicas. Por uma parte, enquanto polaridades resultavam de processos de desenvolvimento nos quais complementaridade estratégica exercia papel decisivo, surgem economias externas de um movimento circular no qual decisões de investir em um ponto no espaço ampliam e diversificam o mercado que, com nova escala, atrai novos investimentos para fazer substituição de importações. Por outra parte, conquanto formações históricas específicas, essas realidades locais apresentavam particularidades que, em confronto com as forças de modernização do capitalismo, produziriam os mais diferentes resultados - configurações, cuja principal marca seria a segmentação estrutural de totalidades duradouras. Em tal contexto, argumentava-se, a convergência pressuposta nos modelos tradicionais seria improvável, e o desenvolvimento, uma expectativa em aberto - uma história com possibilidades múltiplas, ascendentes e descentes.

Esse movimento de ideias foi contido por um tempo significativo. Primeiro, internamente ao campo das ciências regionais, desenvolve-se uma perspectiva funcionalista que produziu teorias do planejamento, como equivalentes de teorias do desenvolvimento, inspiradas na tese da "convergência regional", base do trabalho seminal de Friedman e Alonso (1964). Diferentemente da tese neoclássica na qual a eliminação dos desequilíbrios regionais seria intrínseca à operação dos mercados livres, nos modelos funcionalistas o processo de desenvolvimento regional seria guiado por estratégia política precisa, reservando ao Estado funções tanto de estímulo ao dualismo como de posterior ajustamento e correção - numa dialética cuja síntese presumida seria a repetição da história dos países industrializados, em particular, dos Estados Unidos.
A crise das economias capitalistas ocidentais nos anos setentas e oitentas revelou a falácia dessa presunção, demonstrando, numa prática dolorosa, a inconsistência dos programas de desenvolvimento de países pobres industrialmente subdesenvolvidos e de regiões pobres de países industrializados. A dimensão téchne das ciências regionais se viu contestada. Considerando que, como vimos antes, essa dimensão subordinava todo esse campo de produção de conhecimento, o conjunto entra em crise, que se mostrou longa.

Ao mesmo tempo,porém, a crise real da economia aguçou e expôs reconfigurações importantes na geografia econômica dos países industrializados, com regiões tradicionalmente manufatureiras apresentando sinais graves de declínio, enquanto outras demonstram continuada vitalidade para manter, ou mesmo ampliar, sua capacidade.E mais: apresentam-se novas regiões industriais com vitalidade difícil de presumir havia apenas algumas décadas. Sob outro ângulo, tornou-se evidente que as dinâmicas econômicas assentavam-se sobre bases estruturais diversas - e, em muitos casos, inesperadas por uma perspectiva tradicional - que resultaram, por vezes, de estratégias empresariais orientadas fundamentalmente em economias de escala que requerem (e produzem) cenários dominados por grandes empresas ou conglomerados com unidade de direção; por vezes, de estratégias em que a eficiência das unidades produtivas depende menos (ou mesmo não depende) do tamanho de cada uma e mais da sua rede de relações, tanto cooperativas quanto competitivas, situações em que as economias de escala emergem da atuação de um sem número de pequenas unidades independentes, não obstante disporem, em algum nível, de mecanismos institucionais de orientação e ação (Amaral, 2001).

Nos países em desenvolvimento, como o Brasil, a persistência e o aprofundamento das desigualdades regionais - uma expressão concreta da iniquidade social - reiteravam 
tensões que repunham continuamente a questão regional em foco, atrelada às possibilidades de desenvolvimento.

Não obstante, enquanto essas realidades clamavam por abordagens espacialmente referidas, as "ciências regionais" se retraiam até meados dos anos oitentas. É que as teorias do desenvolvimento sustentadas em convergência regional o planejamento como ciência - já haviam deslocado, ainda nos anos sessentas, suas referências, tanto a teoria linear neoclássica do crescimento quanto as teorias complexas das descontinuidades espaciais e heterogeneidade estrutural, do centro das atenções e interesses acadêmicos. Com a crise econômica geral, o fracasso do planejamento e a contestação do Estado do bem-estar correlatos, não restou mais nada.

Há outros aspectos da mesma questão. Barro e Sala-I-Martin (1995) registram o retraimento da teoria do crescimento desde meados dos anos sessentas, realçando, como causa, um desenvolvimento "propriamente" científico dos modelos explicativos das teorias do crescimento em oposição ao desenvolvimento de um pensamento "prático", menos formal ou menos formalmente sofisticado, apenas apropriado “[...] to give advice to sick countries". Nas próprias palavras:

\footnotetext{
[...] growth theory became excessively technical and steadily lost contact with empirical application. In contrast, development economist, who are required to give advice to sick countries, retained a applied perspective and tended to use models that were technically unsophisticated but empirically useful. The fields of economic development and economic growth drifted apart, and the two areas became almost completely separated.". [Since then,] "...probably because of its lack of empirical relevance, growth theory effectively died as an active research Field [...]. (Barro; SalaI-Martin, 1995, p. 12-13)
}

No que se refere ao deslocamento das teorias do desenvolvimento, Krugman, após constatar que "[...] between 1960 and 1980 high development theory was virtualy buried" e, em seguida, se perguntar"Why did development economics fade away?" (Krugman, 1995, p. 23-29), sugere duas explicações: uma, que qualifica de cínica, associa o declínio à redução da demanda política por esses saberes. Nos seus próprios termos, "[...] the field waned with its funding [...]" (p. 23). O que equivale a dizer que, desvalorizado como téchne, não resistiu como logo. A outra explicação é puramente intelectual: a dificuldade de modelar matematicamente as teorias apresentadas nos anos pós-guerra, geralmente em estilo literário e sem demonstrações formais, teria produzido rejeição crescente pelos praticantes da economia, uma disciplina que cada vez mais investia no rigor matemático de seus tratamentos como forma de legitimação no campo científico.

\section{4_A problemática espacial do desenvolvimento e novas teorias}

Nos anos oitentas, questões do próprio campo científico tiveram importância para a crise das ciências regionais. Há que considerar, porém, outro ponto de vista: as questões regionais, ao lado da pesquisa sobre os fundamentos mais profundos e os determinantes de longo prazo do desenvolvimento, tiveram sua importância empalidecida no período porque se tornaram subordinadas às visões globalizantes $\mathrm{e}$ abstratas da dinâmica social e econômica que acompanharam, orientando, o curso das reformas políticas liberais que marcaram as décadas de oitenta e noventa, como relatamos acima. Poder-se-ia indicar, nessa perspectiva, que a economia regional foi deslocada da pauta acadêmica, porque deslocada da pauta política de mais elevado nível estratégico.

Em tal contexto, reafirma-se a perspectiva mecânica do equilíbrio geral, segundo a qual a existência de regiões 
é fato teoricamente relevante somente quando diferenças marcadas nas variáveis de renda, com implicações na renda per capita, são estatisticamente correlacionáveis a referências espaciais. Todavia, dado que, pelos mecanismos de mercado, os diferenciais de renda tenderiam necessariamente a desaparecer, as regiões seriam "momentos", referências necessariamente transitórias. De modo que, nesse período, a discussão mais acalorada que se produziu no âmbito da economia regional foi, sintomaticamente, a relativa à convergência da renda per capita entre as regiões (Barro; Sala-I-Martin, 1991). A rigor, a economia regional assim orientada "discutia" o fim do seu objeto.

Nos últimos anos, contudo, as teorias do desenvolvimento vêm acusando o impacto de dois conjuntos associados de eventos empíricos e teóricos. Empiricamente, mudanças de padrões de desenvolvimento com implicações territoriais claras têm demandando, tensamente, abordagem espacialmente referida. A isso já nos reportamos.

$\mathrm{O}$ outro conjunto de eventos relevantes refere-se à novidade de que, relacionadas a essas ocorrências empíricas, afloraram novas perspectivas teóricas instrumentadas nas possibilidades heurísticas da noção de auto-organização, fundamento dos paradigmas de não linearidade na evolução dos sistemas complexos. Com utilização crescente pelos cientistas naturais nas últimas décadas, as abordagens complexas e não lineares têm encontrado emprego entre os economistas por permitir operar metodologicamente com desembaraço a representação de realidades fora do equilíbrio - as que, por suposto, abrigam os pressupostos de crescimento e desenvolvimento. Tanto que não tardou a se constatar que,

\section{[...] High development theory was right. [...]: their emphasis on strategic complementarity in investment decisions and on the problem}

of coordination failure did in fact identify important possibilities that are neglected in competitive equilibrium models" (p.28). [So that], "[...] these ideas have had to be rediscovered.." [and] only recently have changes in economics made it possible to reconsider what the development theorist said, and to regain the valuable ideas that have been lost. (Krugman, 1995, p.7)

Por outro lado, ao explorarem as possibilidades das abordagens não lineares e complexas, economistas heterodoxos vêm fornecendo um novo conjunto de ferramentas teóricas que subsidiam uma verdadeira "geographical revenge" (Conti; Giaccaria, 2001, p. 84), no sentido de estabelecer a dimensão local, com toda sua concretude, como entidade intermediária necessária à compreensão do desenvolvimento, a par de situar tal dimensão na amplitude de um mundo em redes. Nessa tarefa, a separação positivista entre as ciências sociais tem sido sistematicamente superada.

\section{1_As teorias do crescimento endógeno}

Os eventos relatados se fizeram como resultado de contribuições, reformulações, avanços, releituras, provindas de praticamente todas as tradições de pensamento da economia. Desde a segunda metade dos anos oitentas, assiste-se a uma revisão de grande significado das teorias neoclássicas do crescimento econômico, resultando nas teorias do crescimento endógeno. Para Barro e Sala-I-Martin (1991), assim como para Romer (1994), a onda inicial de reformulação foi marcada pelos estudos pioneiros de Romer (1986) e Lucas (1988). Já aqui, uma grande novidade: a tradição neoclássica de considerar exógenas em seus modelos as variáveis de progresso técnico, cuja taxa de crescimento determina o crescimento de longo prazo, é rompida em favor da en- 
dogeneização da mudança tecnológica. O resultado mais impressionante é que o crescimento não encontra um teto - poderia continuar indefinidamente, uma vez que os retornos do investimento em largo espectro de bens de capital, incluindo o capital humano, não se reduziam necessariamente ao longo do processo de crescimento. De modo que a tendência de rendimentos decrescentes associada à acumulação de capital parecia relativizada por spillovers marshalianos de conhecimento entre os produtores e por economias externas à formação de capital humano.

Uma nova geração de estudos, iniciada por Romer (1987, 1990), incorpora teorias de mudança tecnológica e imperfeições de mercado e, assim, reforça os resultados anteriores. Além do mais, considerando relevante na realidade do sistema a concorrência imperfeita e os lucros extraordinários que proporciona, aceita a indicação schumpeteriana de que tais ganhos tendem a ser transformados, em proporção maior do que aqueles que resultam de taxa normal de lucro, em investimentos em P\&D capazes de ampliar o conhecimento técnico e gerar economias externas no sistema. Sob tais condições, onde não se verifica ótimo de Pareto, "[...] the long-term growth rate depends on governmental actions (which) therefore has great potential for good or ill through its influence on the long-term rate of growth". (Barro; Sala-I-Martin, 1995, p. 13)

\section{2_As teorias do desenvolvimento endógeno}

As teorias do desenvolvimento, a sua vez, evoluíram em paralelo às teorias do crescimento, sob o impacto de dois trajetos do grande programa de pesquisa do desenvolvimento endógeno, este orientado pela perspectiva comum de que as economias modernas são sistemas complexos, cujo desenvolvimento tem sido determinado por dinâmica associada à complementaridade estratégica escala-diversidade, por desenvolvimento e difusão tecnológica - formação, comunicação, aprendizado - e por estruturações institucionais de coordenação de concorrência e cooperação.

Um trajeto, que chamaremos de lógico-formal, é representado por um grupo de pesquisas empenhadas em demonstrar os fundamentos e consequências lógicas das dinâmicas de retornos crescentes na definição das regiões e aglomerados, testando as propriedades dos sistemas sob tais regimes de dependência de trajetória (não ergodicidade), de potencial ineficiência, de não predicabilidade e de inflexibilidade na explicação da descontinuidade espacial (regiões polarizadas) e, nestas, das segmentações, segregações e dualidades que as conformam como economias reais. Outro trajeto, histórico-estrutural, resultou do empenho em fundamentar a formação e o progresso das forças subjacentes à dinâmica complexa das economias modernas: os fatores estruturais, tecnológicos e institucionais subjacentes ao crescimento e à transformação das economias modernas.

O esforço lógico-formal tem sido intenso (e denso) no afã de unificar, em modelos formalmente consistentes, enunciados provindos de disciplinas, tradições teóricas e gerações distintas. Por um lado, os avanços das teorias do crescimento endógeno, não obstante contemporâneas, precedem e inspiram os esforços para o desenvolvimento endógeno. Para Krugman (1991), os avanços das novas teorias do crescimento tornaram plausível a hipótese de que "[...] increasing returns are in fact a pervasive influence on the economy"; ao mesmo tempo, as novas teorias do crescimento fizeram o contraponto com a neoclássica tradicional levantando a hipótese fundamental para o desenvolvimento, a saber, a de que "[...] these increasing returns give a decisive role to history in determinig the geography of real economies". (Krugman, 1991, p. 10)

Por outro lado, o mesmo Krugman, assim como Brian Arthur, teve alguns dos seus momentos mais brilhantes demonstrando, com o rigor que entende necessário, a fertilidade e a consistência das ideias que marcaram a high 
development theory protagonizada, como já se mencionou, três décadas atrás por economistas como Perroux, Hirschman e Myrdal, ao lado de geógrafos como Christaller (1933), Krugman (1995); Arthur (1996). O primeiro, em companhia de Mahahisa Fujita e Anthony Venables (Fujita, Krugman e Venables, 2000, p. 41-50), incorporou as contribuições pós-keynesianas dos anos sessentas da teoria do multiplicador da base, em particular a extensão dinâmica desse modelo empreendida por Pred (1966). O último, quando tratou dos padrões de localização da indústria, o fez declaradamente sob influência de Jane Jacobs (ver Arthur, 1994, p. xviii); quando da sua importante contribuição sobre tecnologias concorrentes (Arthur, 1996), teve a reconhecida companhia de Paul David $(1975,1985)$ e Rosenberg (1982).

O imenso esforço histórico-estrutural, por seu turno, tem um leito nas pesquisas de economistas schumpeterianos da economia industrial em convergência com a (nova) economia institucional (NEI) e a escola da regulação francesa, de orientação marxista, e os pós-keynesianos de Cambridge. Seus resultados referem-se às regularidades sistêmicas em nível elevado de abstração, enfatizando os fatores tecnológicos, as mediações microeconômicas subjacentes ao crescimento e a transformação das economias modernas. Essas mesmas orientações, apontando, porém, para as mediações meso, que articulam agentes e estruturas, marcam os trabalhos de Rosenberg (2006), Nelson e Winter (1982) e Dosi (2006); a explicitação histórica na constituição de valores e regras (formais ou tácitas) de convivência e permuta tem expressão nos trabalhos seminais de North $(1981,1990)$ e Williamson (1985); a perspectiva marxista de exposição da natureza necessariamente histórica, marcada por grandes regulações das relações sociais, do sistema capitalista, e suas expressões objetivas configura o objeto dos trabalhos de Aglieta (1984), Lipietz (1988) e Boyer (1990).
A par de tudo, tributárias do conjunto, avançam as teorias do desenvolvimento endógeno, com pesquisas orientadas às expressões mais concretas do desenvolvimento - seu plano mais imediato de realização são a dimensão local e as interfaces entre os diferentes sistemas que a conformam como espaço de vida. Isso, e a forma como tal dimensão se situa no mundo, constitui as duas faces do objeto inquirido: as diferentes formas em que se expressam as descontinuidades espaciais e, nelas, as dualidades, segmentações, aglomerações (Taylor; Thrift, 1982, 1983). Assim que, ganham destaque na observação dos modos objetivos de realização das dinâmicas de desenvolvimento - localmente referido, por suposto -, na esteira e no entorno da produção em massa, tanto as formas hierarquizadas que assume a produção concatenada e reflexiva à grande corporação (Scott, 1988; Storper; Walker, 1989) quanto, para muito além dessa, as formas de produção sob especialização flexível, dominadas por relações horizontais difusas (Piori; Sabel, 1984; Sabel,1989); as formas como concretamente se constituem essas aglomerações e quais suas faces organizacionais; as lógicas territoriais precisas que subjazem às economias externas marshalianas eà formação de capital social e como se estabelecem, que papéis desempenham na reestruturação subjacente ao desenvolvimento (Conti; Julien, 1989); por fim, como se constituem tais realidades objetivas e diversas como parte de um único sistema, ou economia-mundo (Conti, 2005).

De tudo, emerge uma discussão do desenvolvimento endógeno caracterizada por sugerir que a dinâmica das sociedades contemporâneas apresenta características bem distintas das que se pressupunha para um mundo estático, descritível pela mecânica do equilíbrio geral. Eis que:

a. $\mathrm{O}$ desenvolvimento de uma economia é um processo multidimensional (economia, sociedade e natureza) de auto-organização que produz necessariamente agrupamentos 
multicêntricos em que se combinam setores baseados em recursos naturais (com raízes e sem mobilidade espacial) com setores baseados em conhecimento (sem raízes e com mobilidade espacial), cuja polarização se explica por retornos crescentes de escala resultantes da combinação de economias internas às empresas, com externalidades, tanto as de caráter tecnológico quanto as pecuniárias, isto é, aquelas produzidas por combinação estratégica entre escala das empresas individualmente ou em agrupamentos especializados, tamanho do mercado e diversidade da produção total. Tal processo:

a.1. é sensível às condições iniciais, a eventos históricos e ao acaso (historicidade);

a.2. tem referência necessária nas delimitações espaciais (territorialidade),

a.3. são irreprodutíveis e intransportáveis (unicidade);

a.4. apresenta múltiplas possibilidades reprodutivas - estados duradouros - no tempo (não previsibilidade e potencial ineficiência);

a.5. apresenta múltiplas possibilidades reprodutivas no espaço por segregações e dualidades articuladas em concorrência ou cooperação (concorrência de trajetória e inflexibilidade);

a.6. tem complexidade crescente com a relação tamanho-diversidade e com a carga de conhecimento que cada movimento reprodutivo, feedback das partes ou do conjunto, contém e processa. b. As articulações entre essas diferentes estruturações, suas dimensões e escalas, deixam-se representar em alto nível de abstração por noções de rede. Conti (2005, p. 228-229) oferece uma representação baseada em dois tipos de redes: redes globais representam articulações entre agentes por trocas recíprocas numa estratégia de globalização em um sistema policêntrico, no qual cada centro ou nodo da rede contribui com recursos específicos; redes locais, por seu turno, representam as relações entre agentes autocontidos em um dado lugar entendido como escala geográfica que permite relações face a face, de reciprocidade e confiança. Com isso, se dispõe de múltiplas possibilidades de agrupamentos nas interações entre local e global.

\section{5_As teorias do desenvolvimento endógeno e suas noções de suporte: trajetória tecnológica, cadeias produtivas, arranjos e sistemas produtivos e inovativos e economias locais}

No esforço de descrever, explicar e acompanhar a evolução de tal mundo, são desenvolvidas categorias para operar as novas referências, sua estruturação e sua dinâmica. Desenvolvem-se novas acepções de empresa, da concatenação entre elas e delas com a base natural e o ambiente social de que faz parte: empresas como sistemas abertos, cadeias produtivas, trajetórias tecnológicas, aglomerados produtivos, economias locais. Todas essas noções se constituem no quadro da teoria dos sistemas complexos, com as propriedades de autopoiesis e dinâmicas de não equilíbrio, para o todo, o global da economia-mundo, e seus componentes - as nações e suas economias nacionais, regionais e locais. A metáfora de redes tem sido acionada como a que mais se ajusta à ideia 
de que a economia-mundo é mais bem representada pela articulação de múltiplos sistemas heterônomos, com graus variados de autonomia, do que por agregação dos valores homogêneos de variáveis que expressariam, em diferentes locais, os mesmos conteúdos e substâncias.

Os elementos que nos permitiriam ver esse mundo de intrínseca complexidade (Potts, 2000) estão, portanto, postos. A vasta gama de resultados de uma pesquisa, hoje já extensa, tem a virtude de estabelecer os sistemas locais como unidades relevantes de análise, situando-os num sistema de redes. Ademais, tem demonstrado capacidade de atribuir a essa situação a dinâmica do desenvolvimento - este derivaria da competitividade angariada nas interações local-global. Todavia, na literatura, são notados pontos criticáveis na abordagem (ver Conti, 2005, p. 229-231): 1) tende a reduzir toda propulsão do desenvolvimento a um processo de aprendizagem coletiva incrustado no próprio sistema local - minimiza, portanto, as fontes de conhecimento e inovação em outras dimensões; 2) vincula os atores ao sistema por simplificações que desconsideram processos gerais de desenvolvimento desigual próprios do capitalismo, portanto, 3) obscurece a dialética entre as diversas escalas de ação e representação e 4) remete o fundamento dinâmico do desenvolvimento à competitividade de lugares e suas estruturações, criando ambiguidades importantes; 5) tende a reduzir o local a sua expressão urbana - pela via da indústria e dos serviços.

Essas questões carecem de tratamento. Para tanto, é necessário esforço de integração e composição categorial e, ao mesmo tempo, um trabalho de elaboração metodológica para que a integração de categorias a que chegaremos possa ser operada na compreensão de realidades empíricas particulares.

Resta uma questão. Possibilitando retratar o mundo de modo complexo, com capacidade de representá-lo com as diversidades pensadas por Milton Santos - resultante da existência de outros subsistemas econômicos que coexistem com a economia moderna -, essa abordagem permitiria reconsiderar as possibilidades do planejamento do desenvolvimento? As teorias do desenvolvimento endógeno, como logo, sustentaria uma téchne, com a qual pudesse contar a política para um planejamento que não seja um instrumento para a manutenção e o agravamento do atraso de regiões pobres e da exacerbação de disparidades sociais?

\section{1_Empresa como sistema aberto}

A noção de empresa como sistema aberto é seminal a tudo mais na elaboração que segue. A noção de empresa sem conteúdo interior, como reclamava Edith Penrose, unidade de um universo homogêneo, ao qual se ajusta organicamente por racionalidade única de maximização de lucro, contida por mecanismo de equilíbrio geral, estacionário (como formula a tradição neoclássica), produtora de uma hierarquia piramidal ditada por concentração e centralização irrestrita (como dita a tradição marxista), imune aos efeitos do ambiente, seja natural, seja social, consumidora incontida de elementos tecnológicos gerados em qualquer lugar; essa noção de empresa é substituída, na convergência heterodoxa do desenvolvimento endógeno, pela empresa protagonista da dinâmica de inovação pela interação contínua - sistêmica - com o entorno na busca de respostas a necessidades concretas da reprodução social (obtenção de produtos e serviços objetos da divisão social do trabalho), mediante problemas, condições e oportunidades que emergem em situações concretas - do ponto de vista institucional e natural - que muito diferem de um lugar a outro (Penrose et al. apud Conti e Giaccaria, 2001, p. 5). Exercitamos essa noção em nosso programa de pesquisa (ver Costa, 2012a; Costa, 2012b).

Importa estabelecer que, como sistemas abertos, empresas ganham sentido quando referidas a contextos - estruturações - sistêmicos: as trajetórias tecnológicas, as ca- 
deias produtivas e de valor, os aglomerados locais (arranjos produtivos locais), os aglomerados regionais - economias locais - e as redes pervasivas que integram tudo. Vejamos, uma a uma, essas noções.

\section{2_Trajetórias tecnológicas}

Produtos, objetos das empresas, em sua constituição física e social, como mercadorias, portanto, são fenômenos de trajetórias tecnológicas: as empresas como sistemas abertos fazem suas combinações tecnológicas, seus sistemas produtivos, absorvendo elementos do ambiente social em convergências orientadas por trajetórias tecnológicas - cada trajetória indica um rumo evolutivo balizado por um padrão técnico, uma heurística de soluções. Sublinhemos aspectos centrais dessa noção: trajetórias tecnológicas são padrões de atividades que resolvem, com base em um paradigma tecnológico, os problemas produtivos que confrontam os processos decisórios de agentes concretos no atendimento de necessidades reprodutivas, em contextos específicos nas dimensões econômica, institucional e social (Dosi, 2006, p. 22-23; Costa, 2009). As particularidades do contexto econômico se estabelecem nos critérios econômicos "[...] que agem como seletores definindo mais ou menos precisamente o trajeto concreto seguido no interior de um conjunto maior de possibilidades" (Dosi, idem, p. 23). Considerando o elevado nível de incerteza que cerca a adoção de tecnologias, o ambiente institucional assume particular relevância na configuração de trajetórias tecnológicas, desde o interesse econômico das organizações, passando pelas respectivas histórias e acúmulos de expertise, até variáveis institucionais stricto sensu, como agências públicas e interesses geopolíticos (Dosi, idem, p. 24-25).

De modo que trajetórias tecnológicas, a par de se constituírem por sistemas intangíveis de conhecimento, têm existência tangível (real-concreta) nos sistemas de maior ampli- tude e complexidade que integram aqueles (sub)sistemas de conhecimento com as instituições que, em plano mediato, os legitimam, como o mercado e os sistemas de valorização simbólica que o acompanha; com as que em plano imediato os difundem, preservam e desenvolvem, e, por fim, com os agentes que os praticam a ponto de internalizá-los como uma postura (habitus, rationale) - mobilizando os objetos tecnológicos (e seus produtores) que os incorporam e a cultura que os precede e absorve.

Tal noção de trajetória tecnológica permeia, em um extremo, a noção de trajetória tecnológica natural (reconhecido por Conti e Giaccaria, 2001, p. 7): a direção em que um padrão tecnológico pode se desenvolver livremente quando (porque) prevalecem condições "normais" de mercado e progresso técnico "normal” (Dosi, 1988; Elster, 1983). Tal percepção pressupõe dependência de trajetória, porém sob condições "equilibradas". A noção de trajetórias concorrentes (Arthur, 1994) sob condições "desequilibradas", inclui, como condição de normalidade, os movimentos "anormais" - a produção de lock in's ascendentes, descendentes ou estacionários (Costa, 2013).

Consideradas como referências estruturais, as trajetórias tecnológicas podem ser a base de representação de uma tessitura da produção social em qualquer escala da economia- mundo, posto que, por elas, se poderia observar a divisão social do trabalho em seu modus operandi técnico e social - na evolução competitiva e cooperativa de capacidades instaladas e competências de operação e gestão submetidas à racionalidade dominante.

As trajetórias tecnológicas têm lugares concretos de operação. Se trajetórias rurais, uma dessas estruturações é constituída pelos sistemas agrários. Os sistemas agrários são configurações territoriais delimitadas por concorrência e cooperação dinâmica entre as trajetórias em torno dos recursos naturais e institucionais ali prevalecentes. Dos 
sistemas agrários, fazem parte arranjos institucionais que determinam como recursos naturais, de conhecimento e de cultura tecnológica são produzidos e distribuídos, das quais relações fundiárias, regras e mecanismos de acesso a sistemas de inovação, como o crédito e organizações de assistência técnica, são expressões.

\section{3_Aglomerados produtivos - Arranjos e Sistemas Produtivos e Inovativos Locais (ASPIL)}

Como sistemas abertos, firmas ganham sentido quando referidas aos contextos em que se ajustam "[...] relações entre empresas e entre estas e as demais instituições [na obtenção de produto específico] dentro de um espaço geográfico definido" (Cassiolato e Lastres, 2003, p. 23). Sistemas regionais, ou regionalizados, têm aqui seu lugar e, neles, a noção de Arranjos e Sistemas Produtivos e Inovativos Locais (ASPIL).

A categoria ASPIL oferece possibilidades de visualizar a existência e reprodução social nas relações que integram a sua esfera "propriamente" econômica, com as esferas social e política (capital humano: nível de cultura e de habilidade dos cidadãos; capital social: nível das organizações da sociedade civil e sua capacidade de gerar e aplicar novos conhecimentos), expressas em totalidades referidas a produtos (lugar sistêmico na divisão social do trabalho) e localidades (lugar geográfico no sistema social) concretos.

Há perspectivas que entendem serem tais arranjos referências estruturais relevantes nas condições em que reinam processos de especialização flexível, apenas no quadro das realidades industriais mais avançadas (Porter, 1989). Em relação a isso, Cassiolato e Lastres (1999; 2003), seguidos por uma já vasta literatura produzida por integrantes da RedeSist, oferecem a visão mais geral de que, em qualquer realidade social do capitalismo, intrinsecamente submetida a tensões para mudar por força de sua participação na divisão social do trabalho por mediação do mercado, a dinâmica de ajustamento produtivo e reprodutivo que responde a tais tensões pelo uso das disponibilidades, sempre locais, de capital humano, de capital físico e capital natural implica, isto é, requer e cria, interações cooperativas entre as unidades mais irredutíveis (unidades produtivas e de consumo), canais de acesso dessas unidades ao saber codificado ou tácito necessário à inovação tecnológica ou social, e de elementos de governança (nódulos estratégicos de coordenação), seja eles formais, seja informais, seja maduros, seja incipientes.

Sobressaem duas condições do ASPIL: ele é uma emergência que se conforma como mesorrealidade local dinâmica (emerge e se desenvolve); ele é, ao mesmo tempo, componente de uma divisão social do trabalho organizada nacional e globalmente.

Um ASPIL situado num lugar qualquer, chamemos $j$, absorve um conjunto de inputs, processa-os nos sistemas produtivos de suas empresas, dando origem a um produto determinado, $i$. Denominemos essa estruturação genérica que produz em $j, i$, de $A S P I L_{j, j}$ Os inputs são produtos de trajetórias tecnológicas que se originam ou tangenciam o lugar $j$. Dessas trajetórias tecnológicas que fornecem pressupostos da produção dos arranjos tratados, há as que operam requerendo dominantemente ativos específicos locais (trajetórias a) e as que operam com dominância de ativos genéricos, de controle supralocal (trajetórias $\beta$ ). Trajetórias a montante, $\alpha$ e $\beta$, são trajetórias constituintes dos arranjos ${ }_{\alpha, \beta} A S P I L_{j, i}$ (ver ilustração na Figura 1).

Porque referidas a um lugar, as empresas de um arranjo recebem em iguais condições, e de modo relativamente passivo, os elementos exógenos das trajetórias $\beta$ e são compelidas ao compartilhamento dos elementos produtivos que têm origem nas trajetórias $\alpha$, levando os eventualmente diferentes sistemas de produção das empresas a convergirem para um dos $Z$ itens do portfólio tecnológico $z$ de produção do produto $i$ nesta economia nacional de $N$ lugares. Um 
Figura 1_ASPIL e trajetórias: trajetórias alfa de base local se relaciona com trajetórias beta, extra local para constituir um ASPIL. Essa é a expressão local de uma trajetória tecnológica de expressão maior que o local

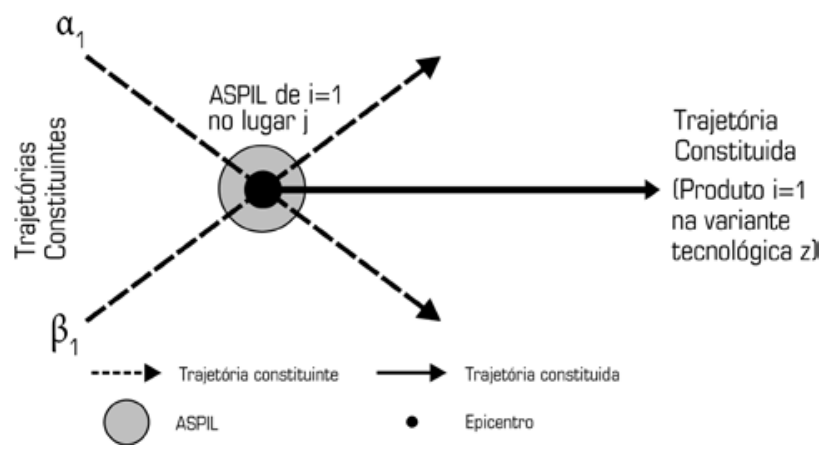

Fonte: Elaboração do autor.

${ }_{a(1), \beta(1)} A S P I L_{j(1), z(1), i_{(1)}}$ seria um arranjo produtivo situado no lugar 1 de uma economia de $\mathrm{N}$ lugares, que participa do atendimento do item 1 do conjunto $i=1 . . . I$ das necessidades da reprodução social daquela economia de $\mathrm{N}$ lugares, mediante condicionantes originados nas características da trajetória $\alpha=1$, a fornecedora de inputs endógenos entre $a$ trajetórias, e $\beta=1$ entre $b$ trajetórias exógenas. Tal contexto coloca a alternativa tecnológica $\mathrm{Z}=1$, de $\mathrm{Z}$ alternativas, como ponto de orientação, ou de atração, dos esforços de mudança das empresas de arranjo produtivo, o que faz dele um constituinte da trajetória $z(1)$ - e esta, uma trajetória constituída pelo ${ }_{a(1), \beta(1)} A S P I L_{\left.j(1), z(1), i_{(1)}\right)}$, é dizer, um ponto de existência da trajetória $z(1)$ da produção nacional de $i(1)$.

\section{4_ASPIL: lugar e estrutura}

Referimo-nos com desenvoltura à noção de lugar nos tópicos anteriores. Todavia, em relação aos ASPIL, como alerta Amaral Filho (2011: 183-85), trata-se de noção difícil. Um ponto parece essencial: a dificuldade trazida pela multiplicidade, seja no que se refere às naturezas, seja no que diz respeito às funções, de agentes e agências envolvidas em um ASPIL. "Como é sabido, esses agentes não se encontram em um só lugar, passível de ser delimitado”.

Uma delimitação sistêmica, porém, é possível, e nisso a noção de epicentro prestaria um serviço: trata-se da ideia de que o ASPIL corresponde aos nexos sistêmicos que agregam a presença de fenômenos de aglomeração de empresas e capacidades, onde contam vetores físicos de distância e recursos naturais, à de centro de decisões influentes e mecanismos de informações e articulação cognitiva com capacidade criativa (Amaral Filho, 2011). Nessa perspectiva, o ASPIL é o epicentro de uma sistema mais abrangente, não definido. A referência territorial da operação desse epicentro seria o lugar do ASPIL.

Queremos retomar a ideia para tornar, entretanto, a noção de epicentro componente do conceito de ASPIL, parte de sua definição como sistema. Assim, a metáfora principal é a de que os arranjos produtivos têm epicentros e periferias. Esses componentes não são definidos espacialmente, mas sim, sistemicamente - têm, porém, referências territoriais necessárias. A periferia é o lugar sistêmico onde operam agentes no contexto das trajetórias constituintes alfa do APL, eventualmente agregando primeiros serviços genéricos concretamente, essas operações se circunscrevem a pontos e manchas no espaço, a locais com nome, que correspondem a jurisdições, município, comunidades.

O epicentro, por sua vez, é o lugar sistêmico do arranjo, constituído das atividades, desempenhadas por suas empresas, de recepção, organização e processamento sob a orientação finalista do ASPIL - isto é, mediante sua condição de constituinte, eis que ponto operante em um lugar, de uma trajetória tecnológica vigente em totalidade mais abrangente.

No epicentro do ASPIL encontra-se sua natureza específica, formatada, em primeiro lugar, pela variante da trajetória onde se situa. Em segundo lugar, a especificidade do 
ASPIL se manifesta no epicentro, eis que sua natureza lá se conforma por operações adaptativas da trajetória, da qual o ASPIL é constituinte, às condições objetivas do território, seus potenciais e limitações; lá, também, dinâmicas propriamente evolutivas podem emergir, favorecidas pelo húmus local.

De modo que, ao lugar sistêmico do epicentro correspondem, também, referências territoriais necessárias: lugares com nomes, jurisdições, municípios onde se dão concretamente as operações de organização e processamento que inoculam o DNA da trajetória da qual o APL é constitutivo. $\mathrm{E}$, dado que todos os elementos que constituem o epicentro usufruem de ganhos de proximidade, espera-se que à centralidade sistêmica corresponda uma centralidade espacial - um lugar de existência cada vez mais visível, definido e proeminente.

Por fim, os ASPIL operam em seus territórios e em territórios alhures: no plano local das relações imediatas e no plano extralocal das relações mediatas. Os resultados, para os ASPIL, das operações para além fronteiras, são os resultados visíveis dos agentes e suas agências no local, no território dos ASPIL. Os resultados dessas operações para os interlocutores que se situam fora das fronteiras do território do ASPIL se mostram, por seu turno, lá. Ter clareza a respeito disso é fundamental para operar metodologicamente as noções que seguem.

\section{5_De ASPIL a setores: um movimento teórico-metodológico de transposição vertical de escala e acesso a sistemas superiores extralocais}

Para a realidade supralocal, $o_{\alpha(1), \beta(1)} A S P I L_{j(1), z(1), i_{(1)}}$ é um elemento de um subconjunto de arranjos que produzem $i(1)$ sob as condições da trajetória tecnológica $z(1)$ em diferentes lugares dos $N$ existentes na economia, cada um deles articulando elementos de trajetórias constituintes a e $\beta$. Tal subconjunto, que representa a própria existência da trajetória $z(1)$ aplicada a $i(1)$, quando composta com os de- mais subconjuntos $z(1 . . Z)$ que produzem $i(1)$ por diferentes tecnologias, formam o setor $i(1)$ : no nível mais alto de abstração da economia nacional de $N$ lugares, de onde ela é vista como um único sistema, $\alpha(1), \beta(1) A S P I L_{j(1), z(1 . . Z), i(1)}$ seria o setor que produz o item 1 da reprodução social.

\section{6_De ASPIL a economia local: um movimento teórico- metodológico de transposição horizontal de escala e acesso a sistemas superiores locais}

Para a realidade local $j(1)$, o arranjo ${ }_{a(1), \beta(1)} A S P I L_{j(1), z(1), i(1)}$ que discutíamos anteriormente é um entre outros arranjos que lá articulam suas diferentes trajetórias a com os recursos que obtém de trajetórias $\beta$ extralocais por distintas tecnologias z. Tal realidade poderá ser descrita como uma estruturação ${ }_{a(1 \ldots a), \beta(1 \ldots b)} A S P I L_{j(1), z(\ldots Z), i(\ldots I)}$, resultante da operação no mesmo lugar 1 dos diferentes arranjos que fazem uma economia local.

Poderíamos enunciar, pois, que a noção de setor da economia nacional comporta a agregação de ASPIL, de mesma finalidade (ou natureza), distribuídos em diferentes lugares, os quais, como economias locais, agregam ASPIL de diferentes naturezas. Com o primeiro movimento se faz um trajeto que transpõe escalas verticalmente, eis que se transpõem as referências sistêmicas, do local ao nacional - do aglomerado ao compartimento, com o que se transpõem níveis de abstração; com o segundo movimento se transpõem escalas horizontalmente, uma vez que, não obstante se alcançar sistemas mais amplos a requerer maior abstração, a escala local estabelece, para ambas as estruturações, a distância requerida à observação. A compreensão da realidade econômica exige, portanto, cinco referências estruturais: empresas como sistemas abertos, trajetórias tecnológicas, ASPIL, setor e a economia local. Uma via operacional para transitar do nível mais concreto dos ASPIL, para os níveis mais abstratos, do setor e da economia local, seria, a compo- 
sição e decomposição respectivas destes últimos com base no primeiro.

Essas seriam operações formalmente corretas. Contudo, teóricas (e praticamente) insuficientes. Isso porque um setor, enquanto uma projeção macroeconômica de ASPIL de mesma natureza em uma delimitação geográfica superior à local, é mais que a soma dos ASPIL. De um lado, porque, nesse nível, se estabelecem questões "amenizadas" no contexto do ASPIL, sobretudo as que resultam das regulações da relação capital/trabalho (sindicatos de trabalhadores e patronais se estruturam por setor), da relação do tipo de atividade, $\mathrm{e}$ do produto que disponibiliza (valor de uso) com o conjunto da produção social - divisão social do trabalho nacional e internacional. Daí afloram questões de governança e de valoração (formação do valor, relações e regimes de preço, regimes fiscais, regimes cambiais) com implicações distributivas que só se manifestam compreensivamente enquanto problemas da reprodução social. Como tal, são passíveis de tratamento apenas no contexto dos constrangimentos objetivos da realização do conjunto da produção de mesma natureza (da região, do país, do mundo) em relação com o conjunto da produção de toda natureza (da região, do país, do mundo). A economia política clássica trata essas relações realçando o papel da concorrência, intra e entre setores produtivos, mediante a lei do valor trabalho e da transformação do valor em preço. Nesse nível de abstração, de onde se observam relações complexas entre empresa e economia, porém com a mediação única do setor, aponta para tendências com grande força determinística. Tais forças devem ser consideradas, mediante a condição, porém, de que operam mediadas por estruturações intermediárias, das quais já tratamos: as trajetórias, os ASPIL, e as economias locais. Devemos, isso posto, considerar o papel das noções de cadeias de produto e valor.

\section{6_Trajetórias tecnológicas e cadeias de valor: tessituras das redes horizontais e verticais que articulam ASPIL como nodos de setores das economias regionais e nacional e nodos das economias locais}

Sublinhemos pontos seminais. Vista a empresa como sistema aberto,o foco da análise deixa de ser a unidade individual fechada, produtiva ou de gestão, e passa a abarcar as relações entre ela e o ambiente, institucional e natural, de corte local ou extralocal, imerso no qual atua, tendo a referência de diferentes estruturações sistêmicas interligadas. As trajetórias tecnológicas constituintes e constituídas dos e pelos ASPIL conformam as interações primárias as quais, nos contextos particulares das economias locais e no interior dos setores que fazem a economia nacional, gerem a produtividade com a qual opera a base produtiva da sociedade.

Importa anotar, isso posto, que as trajetórias se movem por decisões dos agentes orientados por rentabilidade mediada, em última instância, por cadeia produtiva. Tal noção - outra estruturação sistêmica - seja vista como "cadeia de valor" (Porter) ou como "cadeia de produto" (Appelbaum; Gereffi, 1994a, 1994b), tem em Terence Hopkins e Immanuel Wallerstein (Hopkins, Wallerstein, 1986, p. 189) seus formuladores seminais. Para eles, uma cadeia produtiva pode ser definida como "[...] a network of labor and production processes whose end result is a finished commodity". Colocada desse modo, cadeia não se distinguiria de trajetória, eis que ambas têm como resultado final um produto socialmente aceitável, isto é, mercantilizável.

Mas há diferenças a considerar. A noção de trajetória tem no como se produz a qualificação e o fundamento organizador do que se pretende explicitar - diferenciação de capacidades expressas em produtividade. Na noção de cadeia, o fundamento técnico da produção, isto é, o como se estrutura o processo produtivo, a rigor, não importa - o que importa é a observação da forma como o resultado das capacidades or- 
questradas pelas trajetórias, seus produtos homogêneos ou homogeneizáveis adquirem preço, e as implicações que isso representa para os diversos agentes envolvidos - as rentabilidades respectivas. As duas noções já se mostram aqui complementares, visto que as últimas constituem as referências que atuam como filtros (Dosi), para as decisões que selam os destinos das trajetórias concorrentes (Arthur). Não obstante, são diferentes trajetórias de cadeias de valor, já porque uma cadeia produtiva pode valorar a produção de mais de uma trajetória e vice-versa: uma trajetória tecnológica pode ser objeto de uma ou várias cadeias produtivas.

Para nos aproximarmos do nosso objeto: $\mathrm{O}$ açaí, por exemplo, pode ser produzido pela Trajetória-Camponesa. T2 (conf. Distinções em Costa, 2009), por manejo florestal, e pelas Trajetória-Camponesa.T1 e Trajetória-Patronal.T5 em plantações com importantes níveis de mecanização e quimificação. Essas diferentes trajetórias tecnológicas durante muito tempo foram valorizadas pela mesma cadeia: produtor, processador artesanal, consumidor local. Hoje, tanto o açaí extrativo quanto o agrícola têm duas grandes cadeias de valorização: produtor, processador de primeira linha (polpa), processador de segunda linha (alimentos), mercado local; ou produtor, processador de primeira linha (polpa), processador de segunda linha (óleos e nudles), processamento de terceira linha (vários da química fina), produtor final local e mercado final extralocal. Note a participação, em ambas as cadeias produtivas, do arranjo produtivo local que garante a passagem da condição de fruta, objeto das trajetórias $\mathrm{T}_{2}, \mathrm{~T}_{1}$ e T5, para a condição de polpa, constituinte de trajetórias tecnológica de industrialização de alimentos ou de cosméticos.

Vistas assim, cadeias poderiam representar uma tessitura da produção social em qualquer escala, posto que, por elas, se poderia observar a divisão social do trabalho e monitorar o constante desenvolvimento do sistema produtivo (Hopkins; Wallerstein, 1994, p. 17). Aduzimos, entretanto, que,
Figura 2_Trajetórias cadeias de valor

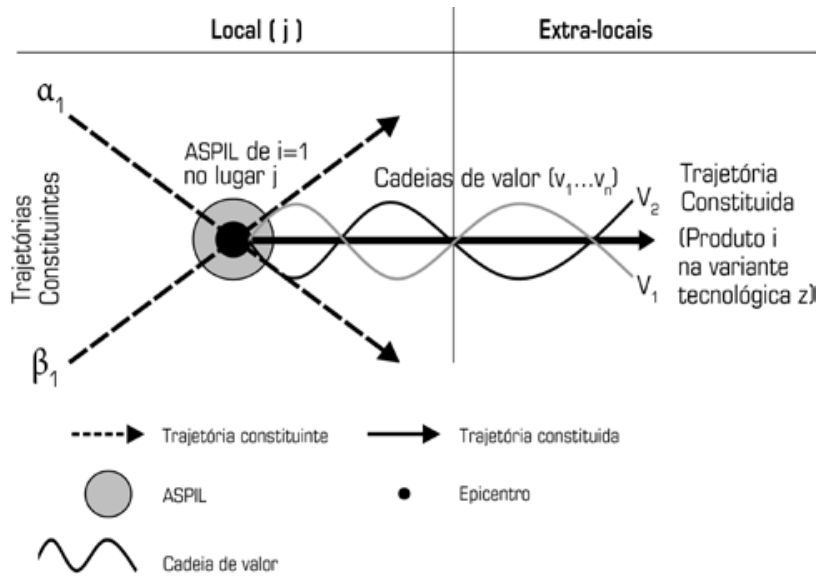

Fonte: Elaboração do autor.

em última instância, tal realidade se fundará em trajetórias tecnológicas. Porque se, em certa escala, diferentes cadeias podem resultar da evolução de uma única trajetória na obtenção de um bem - os caminhos que o produto percorre, conforme sua destinação social ou espacial, estarão nodulados de modo particular, tanto no que se refere a normas a cumprir quanto no que trata hábitos e necessidades a atender, objetivas ou não, tangíveis ou simbólicas. Por outro lado, a observação da realização de uma trajetória pode implicar a consideração das cadeias produtivas que ela supre ou suporta. Os dois conceitos tratam, assim, de tessituras distintas, porém articuladas, da produção social, uma organizada pela formação do valor (produtividade física, associada a funções de produção), a outra pela realização do valor transmutado em preços, em particular do valor excedente, transmutado em lucro e sua distribuição (rentabilidade, associada a condições de transação) (ver ilustração na Figura 2).

Por fim, as cadeias de valor comportam três dimensões: uma estrutura de insumo-produto articulando um conjun- 
to de produtos e serviços numa sequência de atividades de formação de valor; uma territorialidade que identifica a dispersão ou concentração geográfica da produção de matérias-primas e produtos acabados, bem como a localização de redes de comercialização e exportação; e uma estrutura de governança - uma dimensão institucional, estruturada hierarquicamente ou em rede, que determina como os recursos humanos, materiais e financeiros, bem como o lucro, são alocados e circulam no interior da cadeia (Appelbaum; Gereffi, 1994a, p. 42).

\section{7_As economias locais e seus polos - sistemas de conhecimento, crescimento e desenvolvimento}

As estruturações sistêmicas concretas expressas nos conceitos de trajetória tecnológica e cadeia de produto e valor fazem a transposição de escalas que levam o local ao global e vice-versa. Nesse movimento, trajetórias e cadeias se interligam na constituição de ASPIL, os quais, em interações espacialmente contidas, conformam as economias locais. Com isso, temos uma estrutura categorial que permitiria descrever e analisar as redes que articulam esses diferentes níveis. $\mathrm{O}$ que dizer das possibilidades de avaliação, de verificação da direção e sentido apontado pela dinâmica do conjunto - do desenvolvimento da economia e sociedade? Trata-se de questão fundamental.

Um ponto de partida para a discussão seria o de que à condição de desenvolvimento se atribui um processo de crescimento com produtividade crescente: uma dinâmica extensiva, de elevação de escala e capacidade produtiva associada, seja como causa, seja como efeito a uma mudança de qualidade nos fundamentos produtivos da sociedade que se reflita na elevação continuada da produtividade. Tanto a proposição de Kaldor (1966), quanto os modelos de polarização de Krugaman (1991,1995, 1998), a que já nos referimos, têm suposto que a produtividade crescente deriva de economias de escala dinâmicas: o crescimento em tamanho aprofundaria a divisão social do trabalho com efeitos sobre a produtividade. Ambos, Kaldor e Krugman, supõem como fator de formação de ganhos de externalidade o aprendizado difuso que se faz como decorrência das oportunidades associadas a uma expansão. Tratar-se-ia, no entanto, de resultado, mecanicamente alcançado - inferido com linearidade cartesiana - de ganhos de tamanho combinados, no caso de Krugman, com efeitos locacionais derivados dos custos de transporte.

Há que aduzir a essas percepções, de alcance sistêmico, por certo, porém fortemente pautadas por raciocínio lógico-formal, a noção de que a produtividade crescente que fundamenta o desenvolvimento resulta, em perspectiva histórico-estrutural, de capacidades concretas, que emergem em processos dependentes de trajetória, históricos, portanto, da interação consistente de agentes e agências, ações e estruturas que se reproduzem em contextos particulares, constituindo sistemas complexos de conhecimento, regulações e capacidades culturais que forjam a qualidade dos territórios. Com base no trabalho seminal de Freeman (1988), revelando essa dimensão em território nacional como sistema nacional de inovação, desenvolveram-se noções correlatas de sistemas regionais de inovação (Lundval, 2002; Cooke; Morgan, 1998). As noções de ASPIL, que fundamentam o programa da RedeSist, incorporam essa dimensão no nível mais elementar de sua ocorrência (Cassiolato; Lastres, 2003).

Todas essas contribuições tratam a formação dessa dimensão dos sistemas produtivos, essencialmente, como dinâmicas de emergência: elas partilham ontologias comuns. Com efeito, observadas as gêneses, constatam-se estruturações conformadas em trajetórias, cadeias de valor, arranjos produtivos, etc. É que tanto as trajetórias quanto as cadeias organizam governanças e têm suas dinâmicas condicionadas por fontes de conhecimento referidas a sistemas de produção e difusão de saber tecnológico ou gerencial, também 
Figura 3_Economias locais e suas transcendências

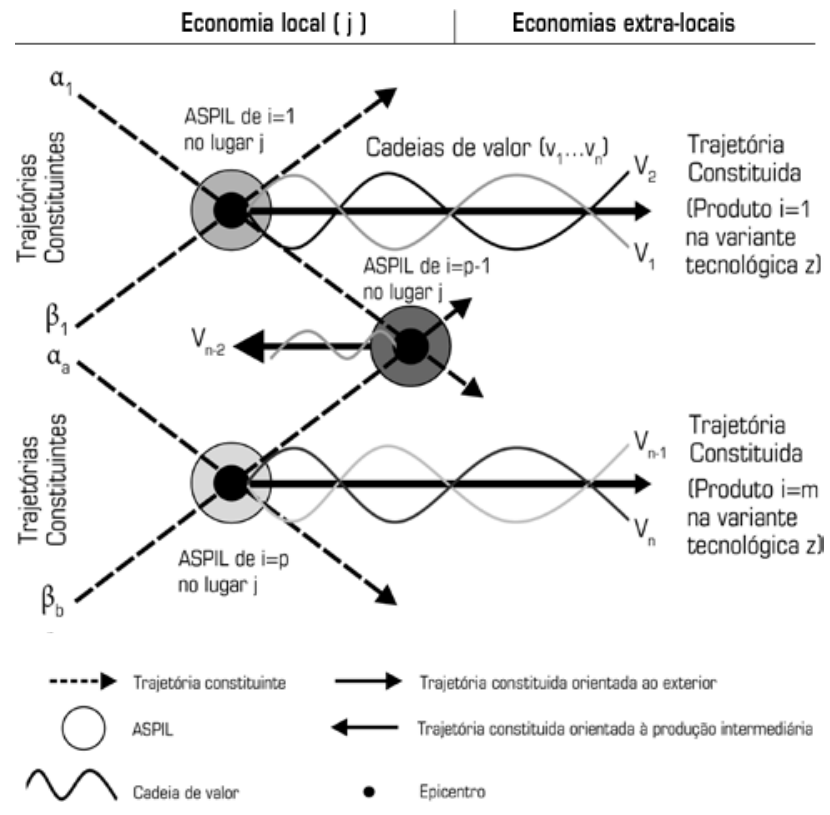

Fonte: Elaboração do autor.

de diferentes níveis - locais, regionais e nacionais - laboratoriais ou tácitos. Assim que, as economias locais, em particular, os seus polos urbanos centrais, são mais que a soma dos ASPIL que as compõem: sobretudo em seus lugares centrais elas abrigam os sistemas locais de conhecimento, inovações e serviços produtivos que se formam em torno das cadeias de valor e trajetórias constituintes dos ASPIL, os quais, por seu turno, mobilizam e contêm conhecimentos e capacidades derivados das trajetórias respectivas por eles constituídas.

Além disso, há transcendências e carências que derivam do conjunto de ASPIL de naturezas diferentes que fazem as economias locais e seus polos. Registre-se que, nesse nível, o local, as externalidades, tanto as positivas (o grau de educação, as disponibilidades infraestruturais de conhecimento, seja de base, como capacidade difusa, habilidades tornadas primárias no lugar, seja avançado, com ênfase em capacidade de direção e criatividade, ao que se associa poder de compra, nível de exigência e grau de organização de consumidores, nível de cooperação dos produtores e de coesão dos trabalhadores) quanto as negativas (efeito da pressão sobre a base natural, efeitos de congestionamento) manifestam-se em plenitude. Não obstante, carências há, cujas expressões e correspondentes formas de atendimento e superação emergem em sistemas extralocais, regionais e nacionais. De um modo ou de outro, a existência e o nível de desenvolvimento desses sistemas carecem explicitação na análise (conhecimento como logo), posto que eles constituem mediações fortes entre expansões em escala e mudanças qualitativas, tornando incertos e não lineares os caminhos da transformação do crescimento em desenvolvimento. Em tudo, a possibilidade da interferência política como parte do próprio processo - da ação objetivada (com o uso desses resultados como techné) ao potenciamento ou à contenção das emergências e estruturações que forjam a dimensão sistêmica que qualifica os lugares e territórios que formam uma região ou um país. A isso retornaremos adiante, quando tratarmos do planejamento.

Importa agora estabelecer que a avaliação dos processos de desenvolvimento exige duas abordagens combinadas: uma que trate do crescimento como extensão e outra que trate da qualidade de seus fundamentos e resultados. Em relação a isso, um primeiro ponto diz respeito à observação da dinâmica do conjunto desde a observação da dinâmica das partes: o que se coloca é se, e como, é possível avaliar, resguardando essas exigências, a dinâmica de trajetórias, de ASPIL e de economias locais, para que se possa avaliar o desenvolvimento das regiões enquanto sistemas de lugares, bem como observar o desenvolvimento do país como o de um sistema de regiões e suas redes. 
A questão foi encaminhada anteriormente, utilizando resultados da Escola da Regulação Francesa (ERF) (Boyer; Petit, 1991) em convergência com pós-keynesianos de Cambridge. Ambos os programas, mirando a avaliação das economias nacionais, sugerem a noção de regime de crescimento com três princípios condicionantes: 1) o regime de demanda ( $R D)$, que descreve os determinantes dos componentes da demanda agregada; 2 ) o regime de produtividade $(R P)$, que explicita os determinantes do progresso técnico e da acumulação. Os $R D$ e $R P$ ocorrem mediante 3) um regime institucional que expressa a interação, naquele tempo e lugar, entre as formas institucionais que organizam as necessidades preponderantes do capitalismo e as formas de produção que ali se reproduzem (Amitrano, 2011).

Recentemente, tem-se procurado discutir desenvolvimento regional nessa perspectiva, em alinhamento com os esteios teóricos do desenvolvimento endógeno: a categoria garante a descrição do processo de crescimento da renda considerando path and space dependency - eis que um regime de crescimento se explica necessariamente em seu contexto, histórica e institucionalmente delimitados (Setterfield, 2010; Roberts; Setterfield, 2006; Lourenço; Bezerra; Pereira, 2011).

Em princípio, as estruturações que fundamentam os territórios, seja as trajetórias tecnológicas e cadeias de valor, seja os aglomerados de ASPIL e economias locais, equivalem-se no sentido de se constituírem, de um lado, nas relações entre produtores intermediários e finais; e destes com aparatos e mecanismos de produção e distribuição de capacidades socialmente (de modo transcendente às empresas) construídas nas interações que formam seus custos de produção e de transação de um item específico da reprodução social. Vistas assim as estruturações do desenvolvimento endógeno, seus movimentos são determinados pelas demandas agregadas (consumo local, nacional, mundial, visto de um modo; consumo das famílias, formação de capital e do governo, visto de outro) daquelas mercadorias a que respectivamente se dedicam, as quais, por seu turno, se expressam nos componentes da renda dos agentes envolvidos - lucros (dos produtores industriais, dos fornecedores de matérias-primas e dos agentes que controlam as transações), salários (de trabalhadores formais e informais) e impostos (em diferentes níveis de governo). $\mathrm{O}$ crescimento da trajetória, do ASPIL e da economia local, sua capacidade de permanência e mudança - ou de mudança para a permanência - portanto, é determinado pela demanda e o Regime da Demanda (RD) é a descrição compreensiva dessa determinação.

Por outro lado, em qualquer caso, a produção resulta da capacidade de processamento instalada, medida pelo acervo de capital físico que possuem as empresas e da capacidade que tenham de mobilizar tal acervo, considerada a disponibilidade de trabalho e os meios de produção. $\mathrm{O}$ crescimento da produção, assim, depende da capacidade de arregimentar recursos para investimentos produtivos, por acumulação endógena (que depende do lucro e, portanto, de um arranjo de partição de resultados, de um lado entre empresa industrial e seus trabalhadores, de outro entre empresas industriais e seus fornecedores, a montante, entre elas e seus cliente, a jusante das cadeias em que se encontram) ou por recursos de crédito. Será observado o crescimento da produtividade por efeito, chamemos, endógeno à própria estruturação, seja trajetória tecnológica, seja aglomerado em qualquer nível, quando o seu crescimento absoluto (em escala) atuar como fonte de criação (justificação econômica) de novas capacidades produtivas em processo de aprofundamento da divisão social do trabalho a ela circunscrita. A forma como se verifica a interação entre crescimento em escala e crescimento em eficiência define o Regime de Produtividade (RP) que se caracteriza pela consistência e desenvolvimento dos sistemas de inovação que o baseiam, exigindo focalizar, para além dos 
tamanhos e escalas, para "[...] as articulações entre conjuntos de diferentes atores relevantes, assim como entre atividades conexas dos diferentes sistemas produtivos e inovativos locais" (Lastres; Cassiolato, 2011, p. 274).

Tal processo, por suposto, se faz como realização da unidade do diverso: integração das diferenças condicionadas pelas distinções naturais e institucionais de localidades delimitadas. De modo que regimes de demanda e regimes de produtividade mantêm relações em contextos institucionais que, afetando a relação entre unidades produtivas industriais ou rurais, trabalhadores e fornecedores - e entre todos esses e a base natural, a terra e os recursos que suporta -, estabelecem os parâmetros que, em última instância, configuram o regime de crescimento.

\section{6_À guisa de conclusão: a necessária revalidação do planejamento como mediação da ação política}

Vimos como teorias do desenvolvimento, operando na perspectiva das ciências regionais, tornaram-se ciências do planejamento do desenvolvimento: como a fusão entre a dimensão logo e a dimensão techné de um estágio de conhecimento sobre a sociedade capitalista e sua dinâmica produziu uma perspectiva mecânica da intervenção política para o desenvolvimento - em última instância, uma visão teleológica da história. Vimos também a severa crítica que a isso se fez, já nos anos setentas. Na vanguarda do questionamento, Milton Santos afirmava que, entre as causas do subdesenvolvimento e da pobreza no "Terceiro Mundo", estaria o planejamento (Santos, 2007, p. 13). Depois, a posteriori da crise do final da década, debitava-se ao planejamento uma sequência de rupturas geográficas, culturais e ecológicas nos países industriais do "primeiro mundo" (Conti, 2005).
O planejamento pressupõe finalidade (o desenvolvimento: como crescimento, como capacidade de consumo, como emancipação, como capacidade, como liberdade?), envolve sujeito (a sociedade em sua dimensão política), objeto, a sociedade (em sua dimensão econômica, em última instância) e processo (ação e retroação coordenadas e controladas por conhecimento e experiência, orientadas a fins compatíveis com devir alternativo, pressuposto superior ao destino - seja ele orientado pela metafísica religiosa, seja pela metafísica do laissez faire). No passado, as críticas se referiam à temeridade de fins definidos por uma ciência, tida com capacidade iluminista de discernir razões de última instância, legitimada pela práxis. Quanto ao sujeito do planejamento, as críticas se referiam à dúvida sobre a efetiva condição do Estado de contrariar as forças econômicas dominantes, da grande corporação e do capital financeiro, de modo a corrigir iniquidades espaciais e sociais. Sobre o objeto, questionava-se se o planejamento do desenvolvimento seria capaz de considerar o todo do corpo social, dadas cisões - a realidade da diversidade da estrutura social e econômica (p. 34); por fim, porém não menos importante, a indagação se seria possível contar com uma ciência capaz de cumprir seu dever de bússola na busca de um futuro sem pobreza, livre e harmônico - desenvolvido.

Transcorrido meio século desde as grandes controvérsias, todas as questões sobre o planejamento voltam a se colocar, iniciando pela mãe de todas elas: os programas de pesquisa que perseguem as hipóteses de convergência têm corroborado a ideia de que é intrínseca ao sistema capitalista a capacidade mecânica de eliminação de iniquidades, mesmo a mais absoluta da pobreza extrema? A rigor, uma questão precede essa: mostra-se o capitalismo liberal, como organizador do sistema-mundo, capaz de cumprir a promessa da modernidade ocidental - de liberdade, igualdade e fraternidade para toda a humanidade? Esta é questão seminal porque, se a 
resposta é não, e se tem, na visão de futuro, consolidadas ideias-forças transformadoras - ideias de justiça e capacidade de permanência, princípios modernos de progresso pautado no ideário do desenvolvimento sustentável, para o qual a sociedade se coloca o dever de equacionar, sem hierarquia, orientações estratégicas de eficiência econômica, equidade social e equilíbrio ecológico; se, enfim, se busca "[...] um futuro sem pobreza, livre e harmônico - desenvolvido", como acima formulamos, nos é dado intervir.

Cabe, porém, perscrutar sobre os fundamentos de conhecimento para tanto. A pergunta-chave será: o estado do conhecimento sobre a sociedade e seu desenvolvimento, cujos avanços reconhecemos anteriormente, possibilita retratar o mundo de modo a apontar para a diversidade de condições sociais, revelar as que são indignas e degradantes, compreender seu sentido sistêmico e abordá-las, ao ponto de apontar caminhos consistentes de desconstrução - consoante à construção de caminhos emancipatórios? Se a resposta for sim, neste caso também nos será exigido intervir, eis que possível fazê-lo minimizando as rupturas criticadas no passado.

Um projeto moderno de desenvolvimento não se realiza com instituições tradicionais. Uma intervenção do Estado com o propósito de promover um desenvolvimento de novo tipo nas regiões críticas do país é tarefa exigente: em conhecimento sobre a realidade (como logo: para o reconhecimento e antevisões; como techné: para orientações e estratégias de intervenção), em capacidade de interação social (novo planejamento do desenvolvimento regional), em capacidade de formação de opinião (nova comunicação), em capacidade de financiamento (inovação institucional rumo à democratização do acesso a recursos públicos) e em capacidade de condução política (projeto de direção, no sentido gramsciano.

Essas capacidades, articuladas, conformam a habilidade social maior que faculta a ação planejada em consonância com a visão complexa e territorializado do desenvolvimento endógeno. Para tanto, exigem-se referências de operação para além do agente ou da empresa. Sugerimos, acima, o ASPIL como elemento central de um planejamento compatível com as perspectivas do desenvolvimento endógeno e sustentável.

A noção de Arranjos e Sistemas Produtivos e Inovativos Locais (ASPIL), tal como discutimos acima, oferece à razão possibilidades de visualizar a existência e reprodução social nas relações que integram a sua esfera "propriamente" econômica com as esferas social e política (capital humano: nível de cultura e de habilidade dos cidadãos; capital social: nível das organizações da sociedade civil e sua capacidade de gerar e aplicar novos conhecimentos), expressas em totalidades referidas necessariamente a localidades concretas. Ademais, em ASPIL se integram trajetórias e cadeias de produto e valor; de ASPIL se constituem setores e de polos trata-se, pois, de estruturação que é ponto de chegada, ponto de partida, ponto de passagem, nodo constitutivo de todas as estruturações categorizadas nas acepções do desenvolvimento endógeno.

A noção é atrativa, assim, como logo, heurística, ciência - como organizadora do conhecimento sobre a coisa como ela é, com grande poder de síntese real-concreta (uma expressão inteligível da complexidade - no sentido metodológico - da realidade social, sem concessões significativas a reduções mecânicas).

Com tais atributos, a noção de ASPIL permite estabelecer o lugar e nomear, concretamente, sujeito e objeto da dinâmica do desenvolvimento. ${ }^{2}$ Por isso, torna-se também atrativa como techné: ou seja, como conhecimento para intervenções objetivadas, tecnologias de controle e coordenação social com vistas a metas estratégicas de devir social, de desenvolvimento, se quiser, endógeno, se quiser, ainda, sustentável. Porque se (e o sujeito aqui oculto é sempre coletivo, social) se conhece lugar, sujeito(s) e objeto(s) das 
formas de reprodução social, se se vislumbram os nexos que os integram em processos virtuosos que transcendem as contradições de última instância (no sentido de Marx, em O Capital), internas a cada unidade produtiva (antagonismo capital/trabalho) e externas a elas (concorrência e lei do valor), poder-se-ia atuar sobre eles, fortalecendo-os, suprindo carências objetivas e tornando-os cada vez mais densos do autoconhecimento produtor da ação comunicativa (Habermas, 1995) que, minimizando os problemas de mensuração/configuração dos contratos, dos pactos (North, 1981; Williamson, 1985), facilitam a cooperação. Precisamente aqui a noção de ASPIL ganha suas duas existências, como logo e como techné. Existências necessariamente associadas, diga-se em adição. Pois, apesar de expressarem timing e premências (tensões) próprias, as noções condicionam-se mutuamente e legitimam-se uma à outra enquanto saber normal (Kuhn, 1982) ou instrumental (Habermas, 1995).

Aqui nos cabe anotar que, no Brasil, as noções de ASPIL, simplificadas no conceito de APL (Arranjos Produtivos Locais), ganharam penetração maior entre pesquisadores e policy makers na condição de techné - pelos seus atributos como referência para a ação. Daí confusões importantes no uso do conceito, tanto em abordagens acadêmicas, quanto em abordagens políticas; seja quando o rejeitam, seja quando o aceitam. Entre os pesquisadores acadêmicos, destaca-se a crítica veemente de Carleal (2011). Para ela, a noção é criticável porque se propõe à exagerada ${ }^{3}$ generalização; porque, tendo como matriz a categoria de sistema regional de inovação, não cumpre os princípios (estruturadores) daquela construção; ${ }^{4}$ a falta de integração com noções correlatas, com as noções de cadeia produtiva e com a noção de setor, que permitiriam alcance territorial para além do Estado federado e alcance sistêmico para além do local/regional: "Assim, a política [de atuação baseada em APL] privilegia o estado, como ente federado [...] fragmenta o território [e] negligencia com as políticas setoriais que também poderiam auxiliar na melhoria do desempenho de determinas aglomerações produtivas" (Carleal, 2011, p. 128).

O arrazoado, se observado como crítica interna ao campo científico, carece de fundamento: há, sim, legitimidade heurística nas noções que apelam à condição sistêmica e multidimensional dos processos produtivos, em todos os níveis, até o da empresa - como expusemos acima, a noção de empresa como sistema aberto é base para os grandes progressos schumpeterianos; por outra parte, é próprio dos arcabouços científicos a generalidade dos conceitos, tanto mais, a depender do grau de abstração que pretenda alcançar. A categoria de setor é generalista - se pretende universal, válida a todos os níveis de funcionamento da economia. Nem por isso, como a autora citada concorda, elas são descartáveis. O que dizer de categorias simples como mercadoria? Ao propor substituir a centralidade e a generalidade da categoria setor pela centralidade e generalidade da categoria APL, programas de pesquisa subvertem por sugerir mudança de paradigma - mas não por heresia condenável no campo científico. A crítica aponta como fonte da perversão pretensa infidelidade à matriz do conceito, à noção de SRI: tratar-se-ia, como um "SRI tropicalizado", de uma caricatura extraída de realidades que não atendem às condições preconizadas pela matriz. Aqui também há impropriedades, uma vez que a referência que se aciona é "[...] proposta de sistema regional de inovação [que] possui um caráter sistêmico, estruturante [por ser] uma construção delibera$d a$ no longo prazo" (Carleal, 2011, p. 128 - grifos meus). Ora, como já mencionamos, o SRI como categoria científica, é emergência sistêmica, é estruturação dependente de trajetória, histórica, portanto. Tal como o APL, aliás. Ambas as noções comportam a ação política. Mas não se definem, a não ser como casos especiais, por ela - como construção deliberada. Há um duplo problema na crítica: quando julga 
a uso científico da noção de APL $(\log o)$ à luz de aplicação política de sua matriz, a SRI (techné); e quando identifica os problemas de aplicação política da noção de APL (techné) a seu papel como orientação de programa de pesquisa com pretensões científicas.

Observado como crítica política à política de APLs, à utilização do conceito como techné, o arrazoado de Carleal ganha sentido. Poder-se-ia, ademais, estender a crítica ao campo científico, se demonstrado que o uso político criticável resulta de parcialidade ou inadequação de tratamento. Fizemos esse exercício antes (Costa, 2006), no ensejo de discutir, como agora, o papel que o conceito poderia assumir num sistema de planejamento baseado em aglomeração, conhecimento, inovação e governança.

Reiteramos os resultados de então: as possibilidades da noção de ASPIL fundamentar um sistema de planejamento regional para o desenvolvimento sustentável da Amazônia são reais. Não obstante, os rumos tomados pela pesquisa acadêmica e as formas de apropriação operacional do conceito têm, em processos de mútuo reforço, levado a dois resultados interligados: 1) o isolamento sistêmico, eis que a noção não é posicionada adequadamente em estruturações e sistemas mais amplos, como indicamos acima, e 2) a parcialidade explanatória: pesquisa-se $(\log o)$ e atua-se (techné) como se seu papel explicativo ou operativo não ultrapassasse o local e só comportasse estruturações de baixa escala. Articuladas, essas carências têm retirado da noção de ASPIL qualquer protagonismo nas dinâmicas de desenvolvimento - têm subtraído os atributos dinâmicos, de largo alcance, que as análises em geral de clustering, tributárias e dependentes das teorias de desenvolvimento endógeno, têm valorizado nos países desenvolvidos.

As exposições que fizemos na seção 3 situam o ASPIL em estrutura categorial que garante sua funcionalidade heurística para qualquer nível de observação. Isso, em teo- ria, lhe facultaria um papel central em um sistema de planejamento que se baseasse nos princípios já enumerados. É, entretanto, necessário mais para que cumpra adequadamente o papel: faz-se mister que se disponha de métodos de leitura que o exponha em seu contexto sistêmico e territorial - que literalmente revele o lugar e a forma de existência do ASPIL. Com isso, poder-se-á atuar sobre ele, seus elementos e estruturações constituintes e constituídas e suas transcendências.

\section{Notas}

${ }^{1}$ Expressão utilizada para designar um movimento abrangente de reforma na gestão da atividade governativa (conf. Hood, 1995).

${ }^{2} \mathrm{O}$ melhor aproveitamento dessa possibilidade exige a consideração do sentido da relação concretoabstrato, isto é, da dialética da construção do "concreto" como produto do pensamento em contexto historicamente delimitado e, assim, a construção do concreto como "concreto pensado", tal como já enunciava Marx em seu mais denso texto metodológico (Marx, 1968). A atualidade metodológica dessa "aventura crítica", o nível de convergência de suas proposições com as questões de complexidade que hoje emergem dos esforços no tratamento das relações açãoestrutura, como já indicamos em diferentes momentos (sobretudo na seção 5), em que se incluem os programas heterodoxos da economia e os programas mais avançados da sociologia e de outras ciências da sociedade, pode ser avaliada em Bensaïd (1999).

3 "No limite, se quer fazer crer que todas as atividades econômicas podem ser organizadas sob $o$ formato de APLs, o que nos parece no mínimo um exagero" (Carleal, 2011, p. 128).

4 "Na verdade, a banalização do conceito de APL fez com que, mediante metodologias simples de identificação de aglomerações produtivas fossem definidos "APLs", mesmo que nenhuma outra das condições discutidas [...do Sistema Regional de Inovação (SRI)...] estejam presentes" (Carleal, 2011, p. 127). 
AGLIETTA, M. Regulation et crisis du capitalisme. Paris: Calmon Lévy, 1976.

AMARAL, J. Desenvolvimento endógeno. In: ENCONTRO NACIONAL DA ANPUR, 2001. Rio de Janeiro. Anais... Rio de Janeiro: ANPUR, 2001. p. 350-365.

AMARAL, J. Arranjos e Sistemas Produtivos e Inovativos Locais. Planejamento e Políticas Públicas, n. 36, jan.-jun. de 2011. Brasília, Ipea.

AMITRANO, C. R. O regime de crescimento econômico brasileiro: uma apreciação sobre o período 1995-2009. In: IPEA. Brasil em desenvolvimento: estado, planejamento e políticas públicas. 1. ed. Brasília: Ipea, 2011. v.1, p. 57-84

APPELBAUM, R. P.; GEREFFI, G. Commodity chains and industrial restructuring in the pacific rim: Garment trade and manufacturing. In: GERIFFI, G.; KORZENIEWICK, M. Commodity chains and global capitalism. West Port, Greenwood Publishing Group, 1994a.
APPELBAUM, R. P.; GEREFFI.

G. Power and profits in the apparel commodity chain.

In: BONACICH, CHENG, L. CHINCHIL, N. A. HAMILTON, N. ONG, P. Global production: The apparel industry in the pacific rim. Philadelphia, Temple University Press, 1994b.

ARTHUR, W. B. Incresasing returns and path dependence in the economy. Michigan, The University of Michigan Press, 1994.

BARRO, R.; SALA-E-MARTIN, X. Convergence across States and Regions. Brookings Papers on Economic Activity, n. 1, p. 107-182, 1991.

BARRO, R.; SALA-E-MARTIN, X. Economic growth. New York: McGrow Hill, 1995.

BENSAID, D. Marx, $o$ intempestivo: grandezas e misérias de uma aventura crítica séculos XIX e XX. Rio de Janeiro: Civilização Brasileira, 1999. $507 \mathrm{p}$.

BERRY, B. J. City Size and Economic Development. In: JACOBSON, L.; PRAKASA, V. (Eds.) Urbanization and National Development. Beverly Hills, Sage, 1971

BOYER, R. A teoria da regulação: uma análise crítica. São Paulo: Nobel, 1990.
BOYER, R.; PETIT, P. Kaldor's growth theories: past, presente and prospect for future. In: EDWARD, J.; NELL, E. J.; SEMMLER, W. Nicholas Kaldor and mainstream economics: confrontation or convergence? London: Macmillan, 1991.

BOURDIEU, P. O campo científico. In: ORTIZ, R.; BOURDIEU, Pierre. Coleção Grandes Cientistas Sociais Sociologia No. 39. São Paulo: Ática, 1994. p. 122-155.

CARDOSO JÚNIOR, J. C. Planejamento governamental e gestão pública no Brasil: elementos para ressignificar o debate e capacitar o Estado. Brasília: Ipea, mar. 2011 (Texto para Discussão, n. 1.584).

CARLEIAL, L. A contribuição neoschumpeteriana e o desenvolvimento regional. In: CRUZ, B. de O. et al. (Org.).

Economia regional e urbana: teorias e métodos com ênfase no Brasil. Brasília: Ipea, 2011.

CARNEIRO, R.; MENICUCCI, T. M. G. Gestão pública no século XXI: As reformas pendentes. IPEA, Brasília-DF, Texto para Discussão 1686, 2011.
CASSIOLATO, J. E.; LASTRES, H. M. M. Inovação, globalização e novas políticas de desenvolvimento industrial e tecnológico. In: CASSIOLATO, J. E.; LASTRES, H. M. M. (Ed.). Globalização e inovação localizada: experiências de sistemas locais do Mercosul. Brasília: IBCT/MCT, 1999.

CASSIOLATO, J. E.; LASTRES, H. M. M. O foco em arranjos produtivos e inovativos locais de pequenas empresas. In: CASSIOLATO, J. E.; LASTRES, H. M. M. (Ed.). Pequena empresa: cooperação e desenvolvimento local. Rio de Janeiro: Relume Dumará, 2003.

CHANG, H. Chutando a escada: a estratégia de desenvolvimento em perspectiva histórica. São Paulo: Ed. UNESP, 2004.

CHRISTALleR, W. Central Places in Southern Germany. Jena, Fischer, 1933.

CONTI, S. Espaço global versus espaço local: Perspectiva sistêmica do desenvolvimento local. In: DINIZ, C. C.; LEMOS, M. B. Economia e território. Belo Horizonte: Editora UFMG, 2005.

CONTI, S.; GIACCARIA, P.

Local development and competitiveness. Dordrecht, Boston, London, Kluwer Academic Publisher, 2001. 
COSTA, F. de A. Formação agropecuária da Amazônia: Os desafios do desenvolvimento sustentável. Belém: NAEA, 2000.

CosTA, F. de A. Arranjos e Sistemas Produtivos e Inovativos Locais - As possibilidades do conceito na constituição de um sistema de planejamento para a Amazônia Revista Brasileira de Inovação, v. 5, n. 1, p. 77-98, 2006.

CosTA, F. de A. Trajetórias tecnológicas como objeto de política de conhecimento para a Amazônia: uma metodologia de delineamento. Revista Brasileira de Inovação, Rio de Janeiro, v. 8, n. 1, p. 35-86, jan./jun., 2009.

CosTA, F. de A. Economia camponesa nas fronteiras do capitalismo: teoria e prática nos EUA e na Amazônia brasileira. Belém: Naea, 2012a (Coleção Economia Política da Amazônia).

COSTA, F. de A. Grande capital e agricultura na Amazônia: o projeto Ford no Tapajós. Belém: Naea, 2012b (Coleção Economia Política da Amazonia).

COSTA, F. de A. Heterogeneidade Estrutural, Tecnologias Concorrentes, Desenvolvimento Sustentável: uma proposta teórica para o tratamento da dinâmica agrária referida a território, com menção especial à Amazônia. Boletim Regional, Urbano e Ambiental (IPEA), v. 8, p. 11-26, 2013.
COOKE, P.; MORGAN, K. The assocional economy: firms, region and innovation. New York, Oxford University Press, 1998.

DAVID, P. Technical choice, innovation, and economic growth. Cambridge: Cambridge University Press, 1975.

DAVID, P. Clio and the economics of qwerty. American Economic Review, 1985.

DINIZ, E. Apresentação. In: DINIZ, E. (Org.). Globalização, Estado e desenvolvimento: Dilemas do Brasil no novo milênio. Rio de Janeiro: FGV, 2007. p. 7-16.

DOSI, G. The nature of the innovation process. In: DOSI, G. et al. (Ed.). Technical change and economic theory. Londres: Pinter, 1988.

DOSI, G. Technological paradigms and technological trajectories. Revista Brasileira de Inovações, v. 5, n. 1, p. 17-32, jan./jun. 2006.

ELSTER, J. Explaining technical change. A case study in the philosophy of science. Cambridge: Cambridge University Press, 1983.

FREEMAN, D. The national system of innovation in historical perspective. Cambridge Journal of Economics, n. 19, p. 5-24, 1995.

FRIEDMAN, J. Regional economic policy for developing areas. The Regional Science Association. Papers and Proceedings, v. 11, 1963.
FRIEDMAN, J.; ALONSO, W. Regional development and planning. A reader. M.I.T. Press, Cambridge, 1964.

FUJITA, M.; KRUGMAN, P.; VENABLES, A. J. Economia espacial: urbanização, prosperidade e desenvolvimento humano no mundo. São Paulo:

Futura, 2000

HADDAD, P. R. A concepção de desenvolvimento regional: A competitividade do agronegócio, estudos de clusters. In: HADDAD, P. R. (Org.). A competitividade do agronegócio e o desenvolvimento regional no Brasil. Estudos de clusters. Brasília, Embrapa/CNPq, 1999. p. 9-36.

HABERMAS, J. Theorie des kommunikativen handelns: handlungsrationalitat und geselschaftliche rationalisierung. Frankfurt: Suhrkamp, 1995. v.1.

HIRSCHMAN, A. The strategy of economic development. New Haven, Yale University Press, 1958. HOOD, C. The new public management in the 1980s: Variations on a theme. Accounting, Organizations and Society, v. 20, n. 2-3, p. 93-109, 1995.

\section{HOOD, C Racionalismo} económico en la gestión pública: De la administración pública progresiva a la nueva gestión pública? In: BRUGUÉ, Q.; SUBIRATS, J. (Orgs.). Lecturas de gestión pública. Madrid: Instituto de Administración Pública, 1996. p. 467-490.
HOPKINS, T. K.; WALLERSTEIN, I. Commodity chains in the world economy prior 1800. Review, vol. 10, n. 1, p. 157-170, 1986.

HOPKINS, T. K.; WALLERSTEIN, I. Commodity chains: Construct and research. In: GERIFFI, G.; KORZENIEWICK, M. Commodity chains and global capitalism. West Port, Greenwood Publishing Group, 1994. p. 17-20.

ILPES - INSTITUTO

LATINOAMERICANO Y DEL CARIBE DE PLANIFICACIÓN ECONÓMICA Y SOCIAL.

Panorama de la gestión pública en América Latina: En la hora de la igualdad. Santiago de Chile: Cepal, jan. 2011. Disponível em: <http://www.eclac.org/ publicaciones/xml/9/42339/ PANORAMA_GP_H_FINAL.pdf $>$.

ISARD. W. Location and spaceeconomy: A general theory relating to spacial location, market areas, land use, trade and urban structure. Cambridge, M.I.T., 1956.

KALDOR, N. Causes of the slow rate of growth in the United Kingdom. Cambridge: Cambridge University Press, 1966. KRUGMAN, P. Development, geography, and economic theory. Cambridge, Teh MIT Press, 1995.

KRUGMAN, P. Geography and trade. Cambridge, The MIT

Press, 1991.

KRUGMAN, P. The selforganizing economy. Oxford, Blackwell, 1998. 
LASH, S.; URRY, J. The end of the organized capitalism. Madison: University of Wisconsin Press, 1987.

LASTRES, H. M.; CASSIOLATO, J. E. Inovação, arranjos produtivos e sistemas de inovação. In: AMARAL FILHO, J.; CARRILLO, J. Trajetórias de desenvolvimento local e regional: uma comparação entre a região Nordeste do Brasil e a Baixa Califórnia, México. Rio de Janeiro: W-Papers, 2011. p. 263-284.

LIPIETZ, A. O capital e seu espaço. São Paulo: Nobel, 1988.

LUCAS JR., R. E. On the mechanics of the economic development. Journal of monetary economics, July 1988.

LUNDVAL, B. A. National system of innovation: towards a theory of innovation and interactive learning. London: Pinter publishers, 2002.

LOURENÇO, A. L. C., BEZERRA, M. M. O., SILVA, M. G., PEREIRA, W. E. N. (2011). De volta a Furtado via Kaldor e Thirwall: as teorias heterodoxas de crescimento como suporte para a retomada do enforque furtadiano da questão regional. Texto apresentado para o encontro da ABEP (mimiografado).

MERHAV, M. Technological dependence, monopoly and growth. Oxford: Pergamon, 1969.

MOE, T. M. La teoría positiva de la burocracia pública. In: ACUÑA, C. H. Lecturas sobre el Estado y las políticas públicas: Retomando el debate de ayer para fortalecer el actual.

Buenos Aires: Proyecto de

Modernización del Estado, 2007.

p. 527-554.

MYRDAL, G. Economic theory and under-developed regions.

London, Duckwoth, 1957.

NELSON, R. N.; WINTER, S.

$\mathrm{G}$. An evolutionary theory of economic change. Hcambridge, Massachusetts, and London, Harvard University Press, 1982.

NORTH, D. Structure and change in economic history. New York

- London, W. W. Norton and

Company, 1981.

NORTH, D. Institutions, institutional change and economic performance.

Cambridge, Cambridge

University Press, 1990.

NORRO, L. Urbanisation et développement économique dans les pays africains: théories et méthodes de recherche. $L a$ croissance urbaine en Afrique noire et à Madagascar. Paris: CNRS, 1972.

PEDERSON, P. O.; STOHR, W. Economic integration and the spacial development of South America. The American behavioral scientist, May/June 1969.

PENROSE, E. A Teoria do Crescimento da Firma. Campinas-SP: Editora

Unicamp, 2006.

PERROUX, F. L'économie du $X X^{\text {eme }}$ siécle. Paris: Presses

Universitaires de France, 1965.
PIORI, M. J.; SABEL, C. F. The second industrial divide. New York: Basic Books, 1984.

\section{PORTER, M. E. A vantagem} competitiva das nações. Rio de Janeiro, Campus, 1989.

POTTS, J. The new evolutionary microeconomics: complexity, conpetence and adaptive behaviour. Chaltenham: Edward Elgar, 2000.

PRED, A. (1966). The Spacial Dynamics of the U.S. urbanindustrial growth. Cambridge, MIT Press.

ROBERTS, M.; SETTERFIELD, M. Endogenous regional growth: a critical approach. Regional Studies, 2006 (Critical Series).

ROLIM, C. F. C. O problema da regionalização. In:

Reestruturação do espaço urbano e regional no Brasil. São Paulo: Hucitec, 1993.

ROMER, P. M. Increasing returns and long run growth. Journal of Political Economy, v. 94, p. 1.002-1.037, 1986.

ROMER, P. M. Growth based on increasing returns due to specialization. American Economic Review, n. 2, v. 72, p. 56-62, May 1987.

ROMER, P. M. Endogenous technological change. Journal of Political Economy, n. 98, p. 71-102, 1990.

ROMER, P. M. The origins of endogenous growth. The Journal of Economic Perspective, n. 1, v. 8, p. 3-22, 1994.
ROSEnBERG, N. Por dentro da caixa-preta: tecnologia e economia. Campinas: Ed. UNICAMP, 2006.

SABEL, C. Flexible specialization and re-emergency of regional economies. In: HIRST, P.; ZAITLIN, J. (Ed.). Reversing industrial decline? Industrial structure and policy in Britain and her competitors. Londres: Routledge, 1989.

SANTOS, M. Economia espacial. São Paulo, Edusp, 2007.

SCOTT, A. J. Metropolis: from the division of labor to urban form. Berkeley/Los Angeles: University of California Press, 1988.

SETTERFIELD, M. Endogenous growth: a Kaldorian approach. In: HARCOURT, G. C.; KRIESLER, P. (Ed.). Handbook of post keynesian economics. Oxford: Oxford University Press, 2010.

STEWART, J. Q. Demografic gravitation: Evidence and application. Sociometry, vol. II, Feb./May 1948.

STORPER, M.; WALKER, R. The capitalist imperative: territory, technology and industrial growth. Oxford: Blackwell, 1989.

TAYLOR, M., THRIFT, N. (1983). Industrial linkage and the segmented economy. In: Regional Studies, v, 17(6), p. 445465. Taylor \& Francis. 
TAYLOR, M., THRIFT, N.

(1983). Business organization, segmentation and location.

Environment and Planing,

v, 14(12), p. 1601-1613.

Taylor \& Francis.

WILLIAMSON, J. G. Regional inequalities and the proceess of national development.

Economic Development and Cultural Change, n. 13, July 1965.

WILLIAMSON, J. G. Regional inequalities and the process of national development: a description of patterns. In: NEEDLEMAN, L. (Ed.). Regional Analysis. Londres: Penguin, 1968. p. 115-146.

WILLIAMSON, J. G. The economic institutions of capitalism. New Apresentado no Seminário Dirur York: Free Press, 1985.

de 5/5/2012.

E-mail de contato do autor:

francisco_de_assis_costa@yahoo.com.br

Artigo recebido em novembro de 2012 e aprovado em agosto de 2013. 